\title{
Year One Summary of X-energy Pebble Fuel Development at ORNL
}

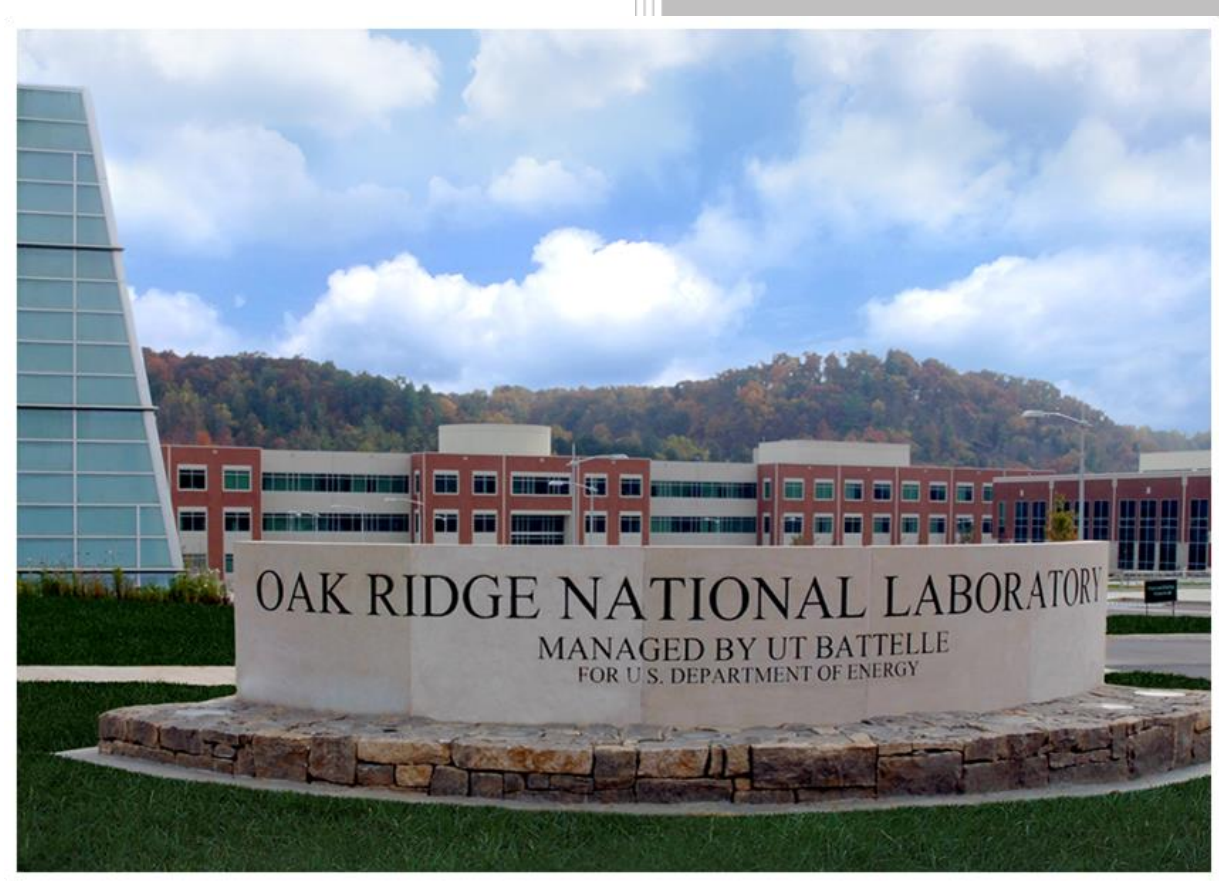

Approved for public release. Distribution is unlimited.
Grant W. Helmreich John D. Hunn Jake W. McMurray Rodney D. Hunt Brian C. Jolly Michael P. Trammell Daniel R. Brown Brandon J. Blamer Tyler J. Reif Howard T. Kim

June 2017 


\title{
DOCUMENT AVAILABILITY
}

Reports produced after January 1, 1996, are generally available free via US Department of Energy (DOE) SciTech Connect.

Website http://www.osti.gov/scitech/

Reports produced before January 1, 1996, may be purchased by members of the public from the following source:

\author{
National Technical Information Service \\ 5285 Port Royal Road \\ Springfield, VA 22161 \\ Telephone 703-605-6000 (1-800-553-6847) \\ TDD 703-487-4639 \\ Fax 703-605-6900 \\ E-mail info@ntis.gov \\ Website http://www.ntis.gov/help/ordermethods.aspx
}

Reports are available to DOE employees, DOE contractors, Energy Technology Data Exchange representatives, and International Nuclear Information System representatives from the following source:

Office of Scientific and Technical Information

PO Box 62

Oak Ridge, TN 37831

Telephone 865-576-8401

Fax 865-576-5728

E-mail reports@osti.gov

Website http://www.osti.gov/contact.html

This report was prepared as an account of work sponsored by an agency of the United States Government. Neither the United States Government nor any agency thereof, nor any of their employees, makes any warranty, express or implied, or assumes any legal liability or responsibility for the accuracy, completeness, or usefulness of any information, apparatus, product, or process disclosed, or represents that its use would not infringe privately owned rights. Reference herein to any specific commercial product, process, or service by trade name, trademark, manufacturer, or otherwise, does not necessarily constitute or imply its endorsement, recommendation, or favoring by the United States Government or any agency thereof. The views and opinions of authors expressed herein do not necessarily state or reflect those of the United States Government or any agency thereof. 


\title{
YEAR ONE SUMMARY OF X-ENERGY PEBBLE FUEL DEVELOPMENT AT ORNL
}

\author{
Grant W. Helmreich \\ John D. Hunn \\ Jake W. McMurray \\ Rodney D. Hunt \\ Brian C. Jolly \\ Michael P. Trammell \\ Daniel R. Brown \\ Brandon J. Blamer \\ Tyler J. Reif \\ Howard T. Kim
}

Date Published: June 2017

\author{
Work sponsored by \\ US DEPARTMENT OF ENERGY \\ Office of Nuclear Energy \\ through an \\ Advanced Reactor Concepts Grant
}

\author{
Prepared by \\ OAK RIDGE NATIONAL LABORATORY \\ Oak Ridge, TN 37831-6283 \\ managed by \\ UT-BATTELLE, LLC \\ for the \\ US DEPARTMENT OF ENERGY \\ under contract DE-AC05-00OR22725
}





\section{CONTENTS}

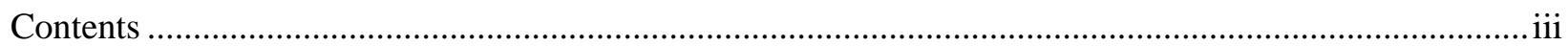

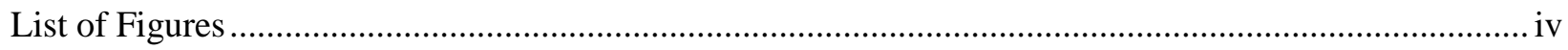

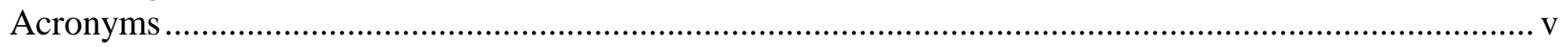

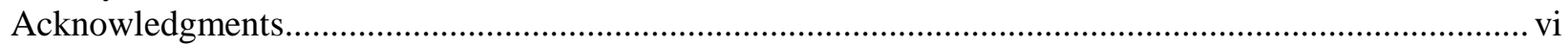

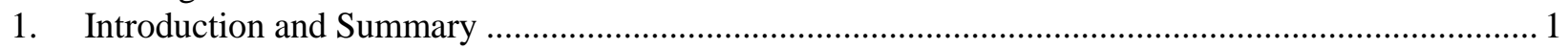

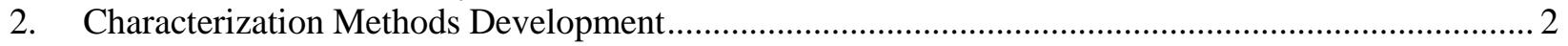

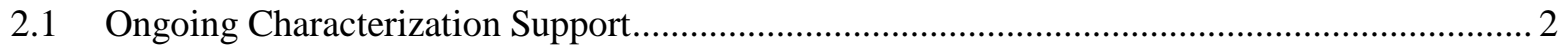

2.2 Development of Gel Sphere and Kernel Characterization Methods ......................................... 2

2.2.1 Gel Sphere Materialographic Methods Development.................................................. 2

2.2.2 Kernel Phase Stoichiometry and Volume-Fraction Measurement ................................. 3

2.3 Development of TRISO Coating Characterization Methods ............................................... 6

2.4 Development of Pebble Characterization Methods........................................................... 8

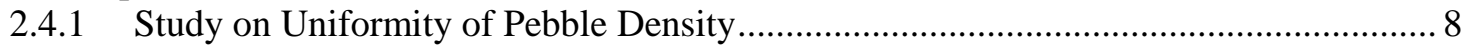

2.4.2 Measurement of Matrix Grain Boundaries and Orientation ........................................ 9

2.4.3 X-ray Tomography of Fuel Cores .......................................................................... 11

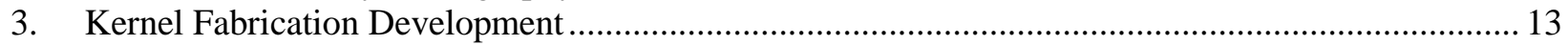

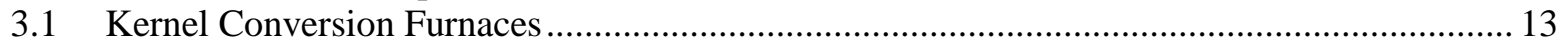

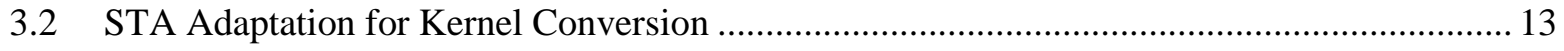

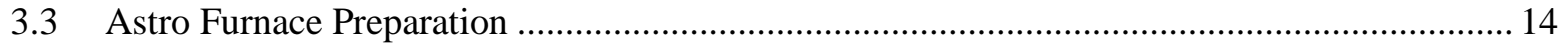

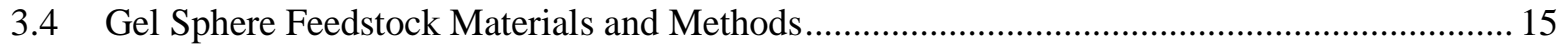

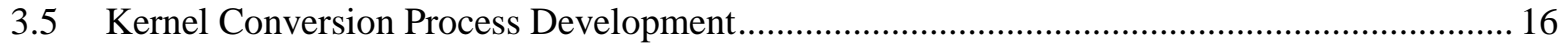

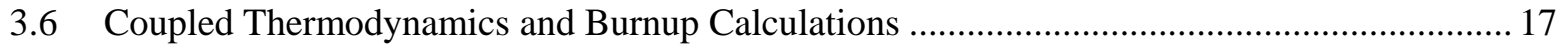

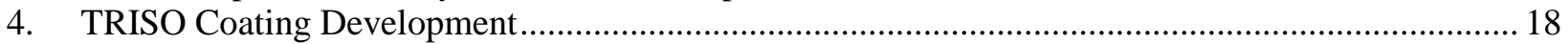

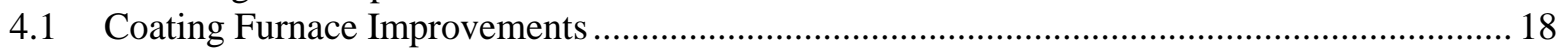

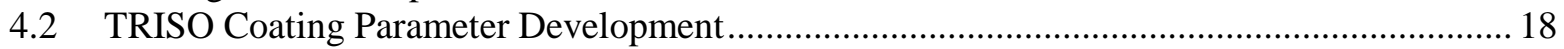

4.3 Surrogate TRISO Production for Overcoating Trials ........................................................... 19

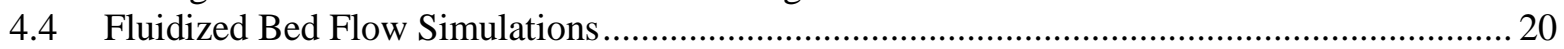

5. Pebble Fabrication Development ............................................................................................. 22

5.1 Pebble Fabrication Equipment Acquisition and Installation............................................... 22

5.2 Pebble Feedstock Materials Testing and Selection ........................................................... 22

5.3 Overcoating Process Development .................................................................. 22

5.4 Pebble Pressing Process Development ........................................................................... 23

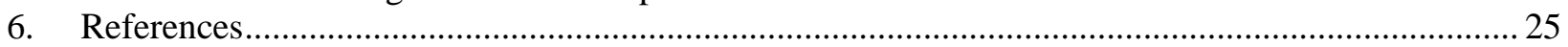




\section{LIST OF FIGURES}

Figure 2-1. Polished cross-section of a gel sphere showing $\mathrm{UO}_{3}$ (bright) and carbon (dark) phases. The dark ring around the gel sphere is material below the current polish plane, viewed through the transparent epoxy.....

Figure 2-2. D2 Phaser used for XRD measurements (left) and example output for UCO kernels (right).

Figure 2-3. LECO C/S Analyzer (left) and O/N Analyzer (right) installed at ORNL for UCO kernel chemistry measurements. .

Figure 2-5. Polished cross-section of a UCO kernel (left) and segregated phases (right). The bright phase is $\mathrm{UC}_{2}$ (as determined by lattice parameters from XRD) and is marked yellow. The gray phase is $\mathrm{UO}_{2}$ and is marked light blue. The dark phase is void and is marked dark blue........ 5

Figure 2-6. Distribution of $\mathrm{C} / \mathrm{U}$ ratios in UCO kernels found by image analysis with geometric corrections and elemental calculations based on phase densities.

Figure 2-7. Distribution of O/U ratios in UCO kernels found by image analysis with geometric corrections and elemental calculations based on phase densities.

Figure 2-8. Tomographic projections of irradiated particles from the AGR program showing clean separation at the buffer/IPyC interface (left) and incomplete separation resulting in IPyC cracking leading to fission product attack on the $\mathrm{SiC}$ (right).....

Figure 2-9. Initial testing of buffer/IPyC interface strength measurement showing crack propagation to and along the interface from nano-indentation.

Figure 2-10. Mercury Porosimeter (left) and Archimedes system (right) used for density measurements of matrix-only pebble fragments.

Figure 2-11. Raw FAA data measured using the 2-MGEM on a matrix-only compact (top) and processed FAA data clustered into grains (bottom). The left of the images is the center of the compact, while the right of the images is the edge. Note that the extrema of FAA (blue and red) represent angles of $0^{\circ}$ and $180^{\circ}$, and are thus very close in orientation.

Figure 2-12. Polar histogram plots of grain orientations near the center of a matrix-only compact showing a uniform distribution of orientations (left) and near the edge showing a preference toward orientations perpendicular to the edge (right).

Figure 2-13. Three-dimensional representation of a surrogate kernel fuel core imaged by XRT.

Figure 2-14. Distribution of nearest-neighbor distances for $\sim 30,000$ surrogate kernels in a fuel core....... 12

Figure 3-1. STA furnace used for small-scale kernel conversion........................................................... 14

Figure 3-2. Astro Furnace in preparation for large-scale kernel conversions......................................... 14

Figure 3-3. Gel spheres falling through silicon oil gelation medium after dispensing from vibrating nozzle.

Figure 3-4. Polished cross-sections of UCO kernels without carbide skin (left) and with carbide skin (right)......

Figure 4-1. Polished cross-section of particles used for coating parameter development.

Figure 4-2. Polished cross-section of surrogate kernel particles coated with thin buffer to match target particle density.

Figure 4-3. Simulation of particles in a fluidized bed at various stages of fluidization. Red areas represent large numbers of particles, white areas represent fewer particles, and blue areas represent very few particles.

Figure 5-1. Overcoater installed at ORNL (top), TRISO particles loaded in the overcoater chamber

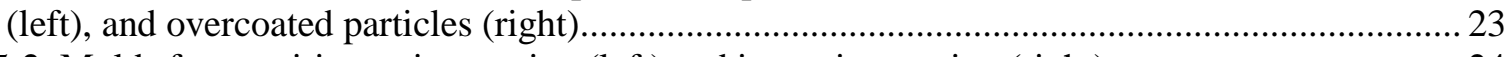

Figure 5-2. Molds for quasi-isostatic pressing (left) and isostatic pressing (right)..................................2 24

Figure 5-3. Pressed matrix-only pebble (left) and fuel core (right). 


\section{ACRONYMS}

2-MGEM Two-Modulator Generalized Ellipsometry Microscope

AGR

ARC-Xe

CVD

FAA

ICP

IPyC

OPyC

ORNL

PIP

$\mathrm{PyC}$

$\mathrm{SiC}$

Advanced Gas Reactor (Fuel Development and Qualification Program)

Advanced Reactor Concepts X-energy (ARC-Xe) Pebble Fuel Development Project

Chemical vapor deposition

Fast-Axis Angle

Inductively-Coupled Plasma mass spectrometry

Inner pyrolytic carbon (TRISO layer)

Outer pyrolytic carbon (TRISO layer)

Oak Ridge National Laboratory

Product Inspection Plan

Pyrolytic carbon or pyrocarbon

TRISO

UCO

Silicon carbide (TRISO layer)

Tristructural-isotropic (coated particles)

Uranium carbide/uranium oxide mixture (fuel kernels) 


\section{ACKNOWLEDGMENTS}

This work was sponsored by the U.S. Department of Energy, Office of Nuclear Energy, through an Advanced Reactor Concepts grant to solve design and fuel development challenges for the Xe-100 Pebble Bed Advanced Reactor. Significant support for this work was provided by John Dyer, Darren Skitt, and Austin Schumacher. 


\section{INTRODUCTION AND SUMMARY}

The Advanced Reactor Concepts X-energy (ARC-Xe) Pebble Fuel Development project at Oak Ridge National Laboratory (ORNL) has successfully completed its first year, having made excellent progress in accomplishing programmatic objectives. The primary focus of research at ORNL in support of X-energy has been the training of X-energy fuel fabrication engineers and the establishment of US pebble fuel production capabilities able to supply the Xe-100 pebble-bed reactor. These efforts have been strongly supported by particle fuel fabrication and characterization expertise present at ORNL from the Advanced Gas Reactor (AGR) Fuel Development and Qualification Program.

The production of pebble fuel is a multi-step process involving kernel fabrication, deposition of several coating layers to form TRISO particles, and finally overcoating and pressing of TRISO particles into a spherical fuel pebble. Each of these fabrication steps also require significant characterization support to determine the quality of the product material and to serve as a critical feedback into process development. Teams in each of the three fabrication steps, as well as characterization, have been formed with X-energy detailees at ORNL and ORNL staff with particle fuel expertise. Each of these groups work in two primary areas: working independently to develop and optimize methods and procedures relevant to their own section of pebble fuel fabrication, and working collaboratively to provide necessary materials and support to the other groups. This arrangement has been highly effective in rapidly advancing the implementation of pebble fuel fabrication capabilities and improving upon existing methods.

Over the first year of the ARC-Xe project at ORNL, each of the four working groups have made excellent progress, laying the foundation for further development work and providing high-value results to support the development of the Xe-100 pebble-bed reactor. These achievements are described in the following sections, along with ongoing work and future directions for research and development. In brief, the characterization team has provided rapid feedback to support ongoing development of fabrication processes while also developing groundbreaking new characterization methods to address gaps in prior TRISO particle fuel characterization work. The kernel fabrication team has developed recipes for gelsphere feedstock production and kernel conversion and has begun deeper study of relevant thermodynamic mechanisms while also preparing for scale-up of the production process. The TRISO coating team has completed initial tuning of coating parameters and has supplied significant quantities of coated material (with non-uranium surrogate kernels) to support initial pebble pressing development. Finally, the pebble fabrication team has completed initial scoping studies on graphite and resin pebble matrix materials, particle overcoating, and pebble pressing methods, and has successfully produced the first surrogate-TRISO particle fuel pebble cores. In all of these endeavors, X-energy detailees at ORNL have been intimately involved and taken lead roles to ensure effective transfer of the relevant knowledge and capabilities necessary for pebble fuel fabrication.

The results presented in this report are intended to provide a summary of the overall accomplishments of the project in the past year suitable for unlimited release. As such, full technical details are withheld in many cases, particularly when dealing with specific fabrication methods or information which may be export-controlled or deemed proprietary. These technical details are well-documented in internal reports and communications, both at ORNL and X-energy. 


\section{CHARACTERIZATION METHODS DEVELOPMENT}

\subsection{ONGOING CHARACTERIZATION SUPPORT}

In addition to developing new characterization methods as dictated by programmatic needs, the characterization team provides continuous and ongoing analysis in support of the fuel fabrication teams. A range of characterization procedures have been previously established at ORNL as a part of the Advanced Gas Reactor Fuel Development and Qualification Program. Improvements to many of these methods utilizing newer technology and automation have been implemented, improving turnaround time on analyses to enable rapid fuel fabrication development and enhance future production-scale quality control activities. Typically-applied characterization methods include measurement of kernel weight, size, shape, density, and phase fractions and measurement of thickness, density, and microstructure for TRISO coating layers. In addition, the characterization team provides regular upgrading of kernels and TRISO particle lots by sorting particles by shape or size with vibrating tablers and roller-micrometers, respectively, to remove aspherical kernels and particles and to limit the range of kernel or particle diameters within a given lot of material.

These analysis methods are critical to both fuel fabrication development and fuel qualification, and comprise an important body of institutional knowledge for future fuel fabrication endeavors by X-energy. As such, Daniel Brown, the X-energy detailee at ORNL assigned to characterization work, has been trained in each characterization method as opportunities arose within the scope of the project. After the first year, Dan has demonstrated mastery of a wide range of characterization methods, covering many of the techniques relevant to TRISO kernel and particle characterization. This training will continue into the remaining AGR characterization methods as the project continues to ensure that the relevant knowledge and skills are fully transferred to X-energy personnel.

\subsection{DEVELOPMENT OF GEL SPHERE AND KERNEL CHARACTERIZATION METHODS}

Developing a thorough understanding of the nature of UCO kernels at each stage of the conversion process, from gel spheres to fully converted kernels, has been a primary focus for the kernel fabrication team in the past year. To support that effort, the characterization team has developed and implemented a Product Inspection Plan detailing characterization steps to be performed at each stage of kernel conversion which provide a complete picture of the nature of the material at each stage. Characterization methods included measurement of kernel size, shape, and density, as well as determination of constituent carbide and oxide phase stoichiometries, fractions, and distributions. While procedures for some of these methods were inherited from the AGR program, others were developed and implemented from scratch.

\subsubsection{Gel Sphere Materialographic Methods Development}

Characterization of carbon dispersion within gel spheres before conversion was one of the new methods developed this year. It was expected that this dispersion was an important factor in determining the microstructure and completeness of the converted kernels. Mounting and polishing methods for crosssectional imaging were already well developed for UCO kernels and TRISO particles; however, the unique nature of gel spheres required new materialographic methods to be implemented. The two primary challenges to materialographic preparation of gel spheres are their sensitivity to heat and the relative softness of the material. Standard materialographic procedures were modified to achieve the programmatic objective of characterization of the carbon dispersion within gel spheres, which eventually confirmed initial hypotheses that this dispersion was a critical factor in the quality of the converted UCO kernels. An optical microscopy image of a polished gel sphere cross-section in which the $\mathrm{UO}_{3}$ and carbon phases are clearly identifiable is shown in Figure 2-1. 


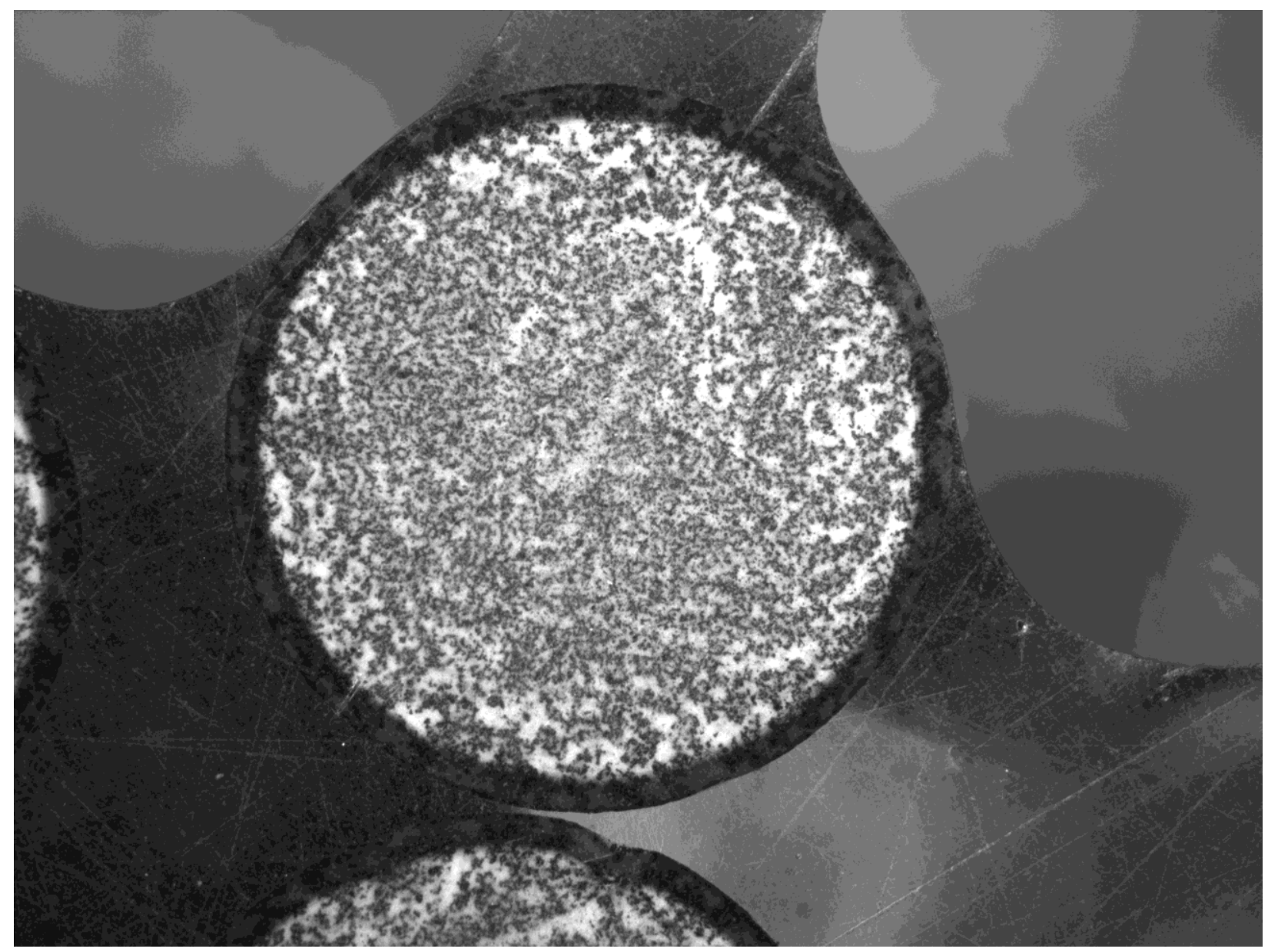

Figure 2-1. Polished cross-section of a gel sphere showing $\mathrm{UO}_{3}$ (bright) and carbon (dark) phases. The dark ring around the gel sphere is material below the current polish plane, viewed through the transparent epoxy.

\subsubsection{Kernel Phase Stoichiometry and Volume-Fraction Measurement}

Significant work has been completed on the development of new characterization methods and capabilities related to identification of the phase stoichiometries, fractions, and distributions of converted UCO kernels. X-ray Diffraction (XRD) has been used for determination of the bulk fractions of $\mathrm{UO}_{2}$, $\mathrm{UC}_{2}$, and UC. Measurement of these fractions is important both for matching the optimal content of uranium, oxygen, and carbon for irradiation performance as well as ensuring full conversion of monocarbide to dicarbide is achieved, as uranium monocarbide is not stable at the temperatures used for coating and pebble making. While XRD has been used previously for kernel phase identification, significant improvements have been made to both sample preparation and analysis methods. An issue was identified and resolved in sample preparation which had the potential to introduce a systematic error due to grain size-based mobility differences between phases in powder samples. Resolution of this issue resulted in significantly improved consistency in measured phase fractions. Improvements to analysis methods have centered on refinements to the curve-fitting process used to find and measure characteristic diffraction peaks for each phase. Figure 2-2 shows the x-ray powder diffractometer used for these measurements, as well as an example of the output spectrum measured for UCO kernels. 


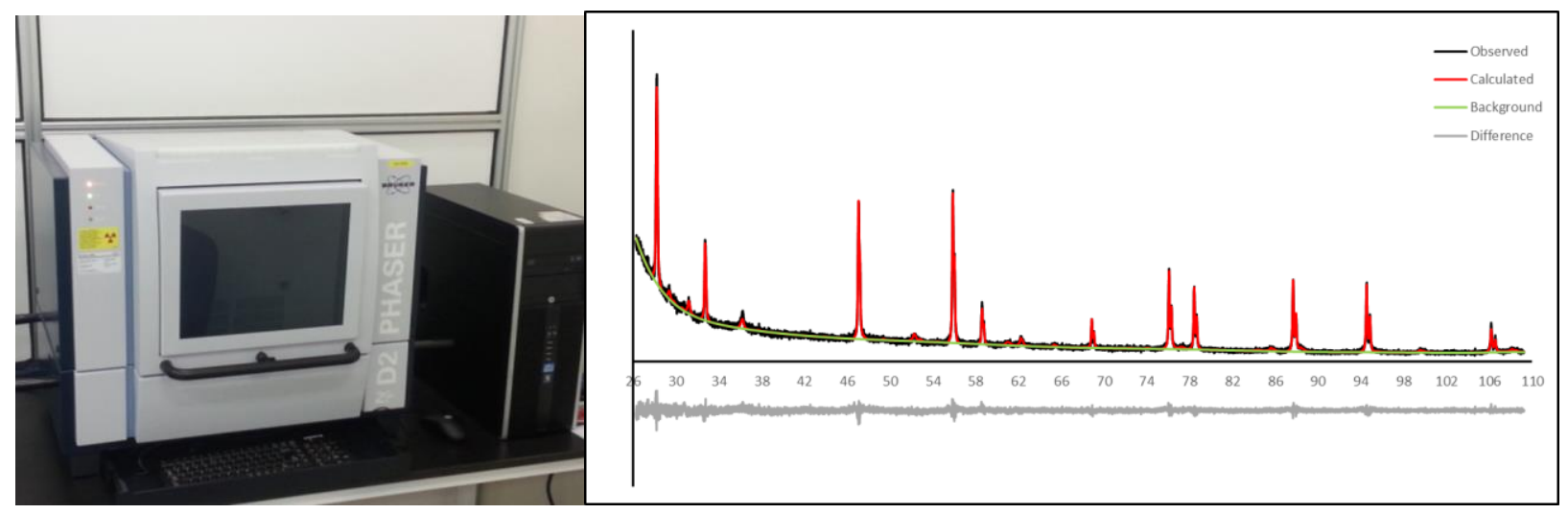

Figure 2-2. D2 Phaser used for XRD measurements (left) and example output for UCO kernels (right).

Two new instruments have been purchased by X-energy and installed at ORNL to provide a robust chemistry analysis suite for UCO kernel characterization: a LECO Carbon/Sulfur Analyzer and a LECO Oxygen/Nitrogen Analyzer. These instruments perform combustion analysis to accurately measure the masses of secondary elements within bulk kernel samples. Combining these results with mean uranium loading data from Davies-Gray analysis will provide an accurate measure of the bulk masses of uranium, oxygen, and carbon within the UCO kernels, confirming the phase fraction results determined by XRD. These instruments have been installed and tested at ORNL, and development of relevant characterization procedures is underway. The installed LECO units are shown in Figure 2-3.

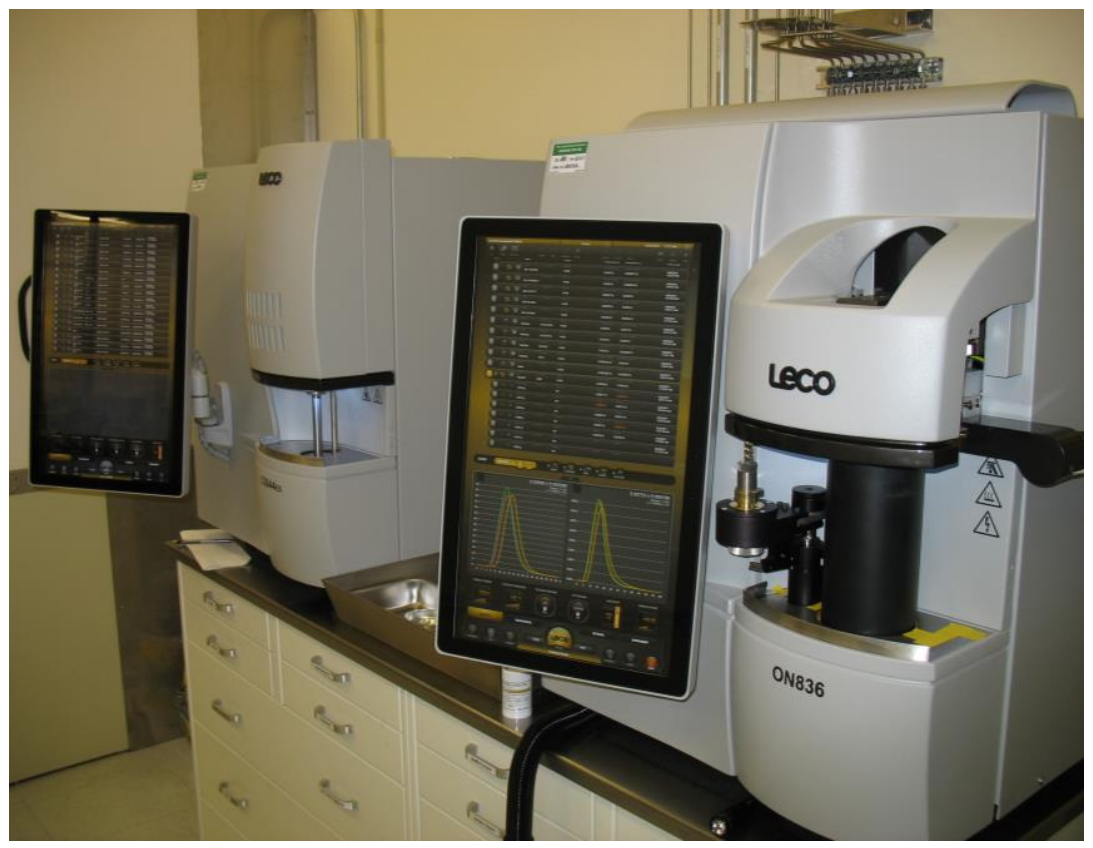

Figure 2-3. LECO C/S Analyzer (left) and O/N Analyzer (right) installed at ORNL for UCO kernel chemistry measurements.

In addition to the bulk phase fraction and chemistry analysis methods which are being developed, a major breakthrough has been accomplished in the determination of individual kernel phase fractions, which has produced unprecedented data on the distribution of phases from kernel to kernel. Image processing software has been developed which identifies carbide, oxide, and void phases within polished kernel cross-sections based on relative brightness, as shown in Figure 2-4 
Areal fractions of each phase are converted to volumetric fractions by the application of a polish-down correction and a geometric conversion of the inner and outer regions of the kernel from nested circles into nested spheres. These volumetric phase fractions may then be converted into relative elemental fractions based on the density and stoichiometry of each phase. This process may be rapidly performed on a large number of kernels using automated imaging and processing methods, producing information on the distribution of phase fractions from kernel to kernel as well as the bulk average, as shown in Figure 2-5 and Figure 2-6. This data fills a significant gap from the AGR program, as only bulk values for phase fractions have been previously measured and the need for identifying abnormal phase concentrations in individual UCO kernels has long been identified as important for good quality control. The mean results from this method have been validated against legacy AGR kernels, and it is expected that this characterization tool will be directly employed in future TRISO fuel qualification efforts and added to the fuel specification. A publication detailing this method is expected within the next year.
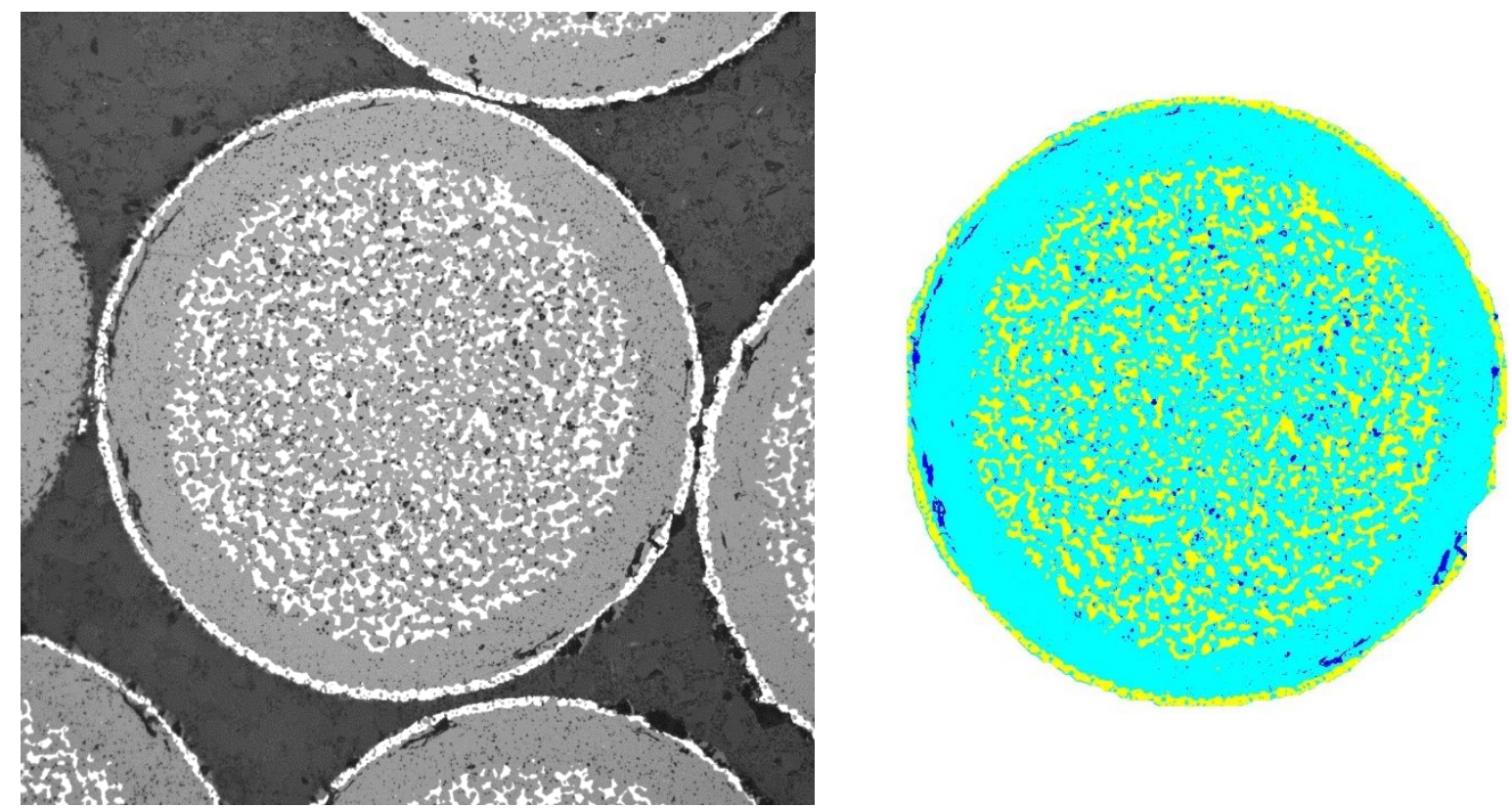

Figure 2-4. Polished cross-section of a UCO kernel (left) and segregated phases (right). The bright phase is $\mathrm{UC}_{2}$ (as determined by lattice parameters from XRD) and is marked yellow. The gray phase is $\mathrm{UO}_{2}$ and is marked light blue. The dark phase is void and is marked dark blue. 


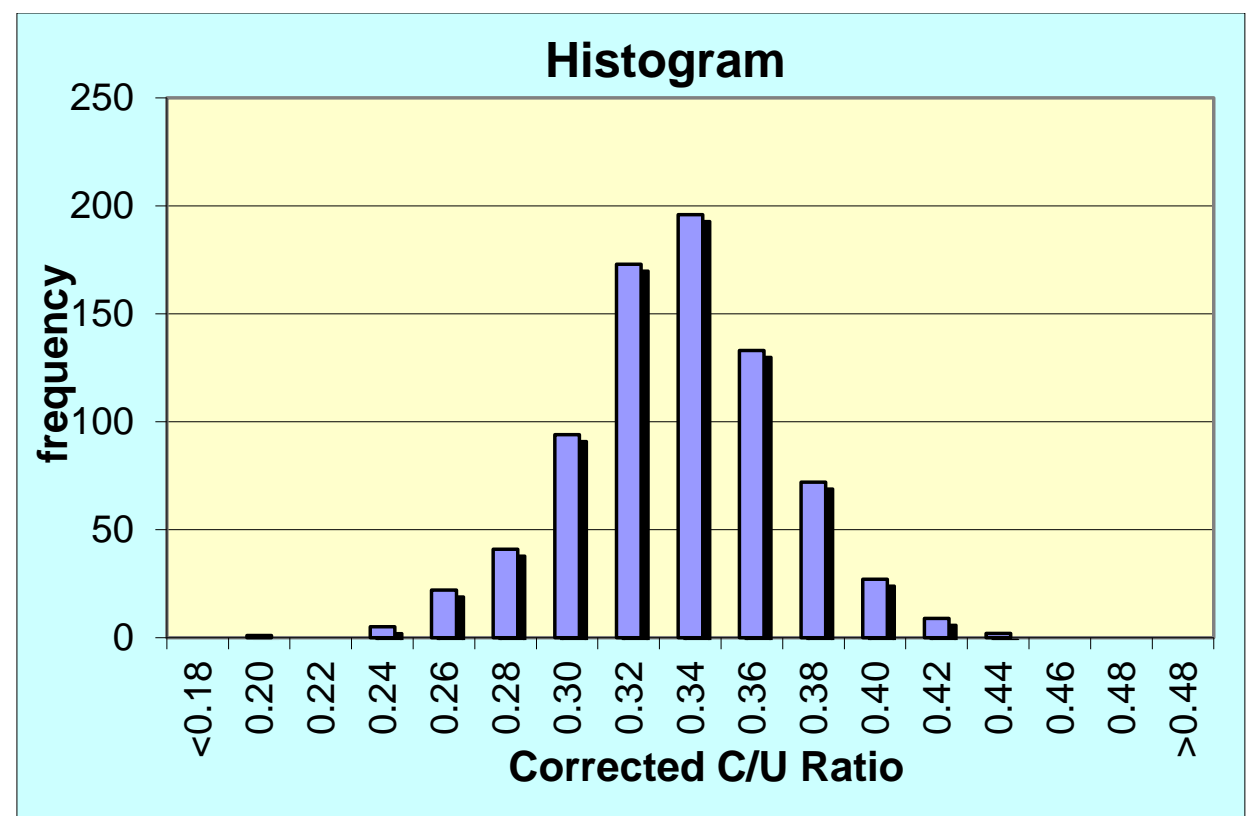

Figure 2-5. Distribution of C/U ratios in UCO kernels found by image analysis with geometric corrections and elemental calculations based on phase densities.

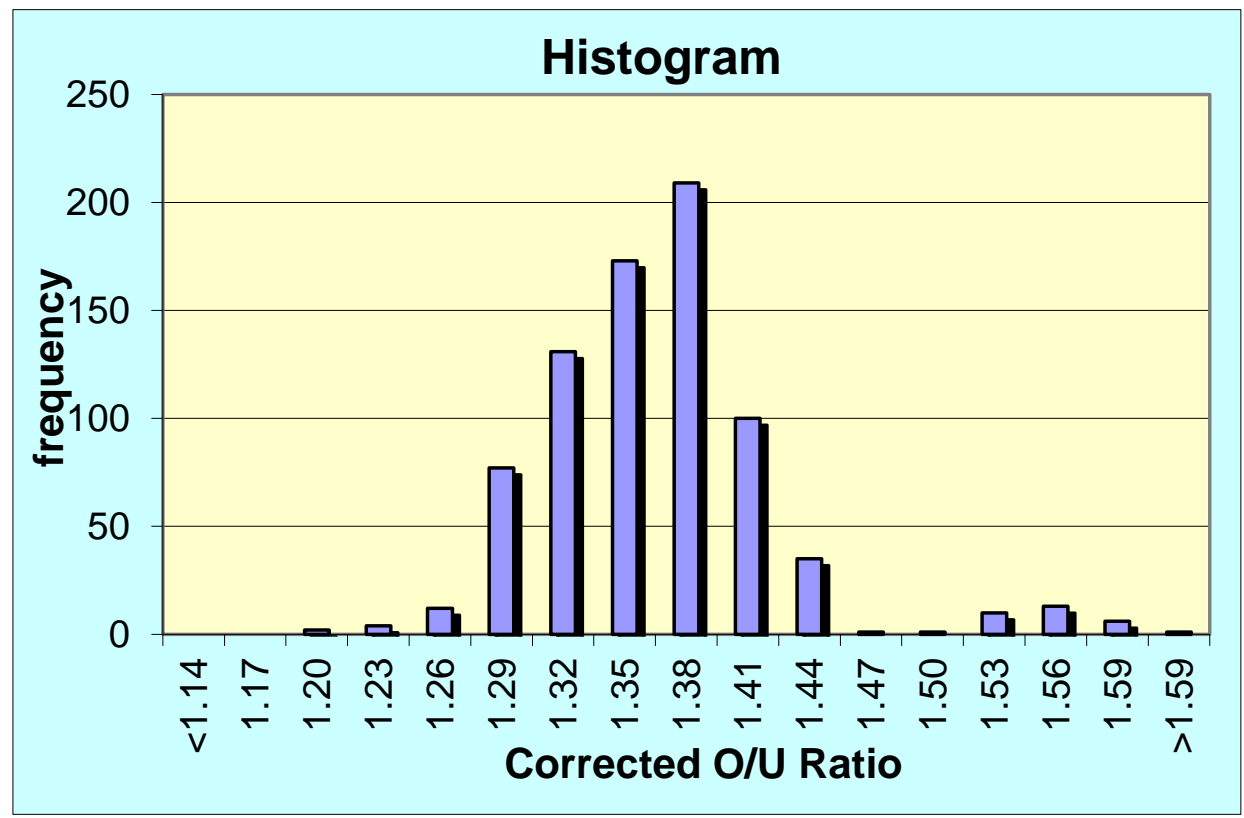

Figure 2-6. Distribution of $\mathrm{O} / \mathrm{U}$ ratios in UCO kernels found by image analysis with geometric corrections and elemental calculations based on phase densities.

\subsection{DEVELOPMENT OF TRISO COATING CHARACTERIZATION METHODS}

Characterization methods for TRISO coating layers were highly developed in the AGR program, and as such significantly less development work has been required for TRISO-coating characterization methods. The primary area in which new characterization methods are required for TRISO coatings is the measurement of buffer/IPyC bond strength. Recent post-irradiation examination research at ORNL under the AGR program has shown that an important potential coating failure mechanisms for TRISO particles during irradiation is cracking of the IPyC layer due to densification of the buffer layer when it is strongly 
bonded to the IPyC. Cracks in the IPyC layer can eventually lead to fission product attack on the SiC layer (Hunn et al. 2014), as shown in Figure 2-7. Based on this mechanism, it is known that a relatively low bond strength between the buffer and IPyC layers is desirable; however, no method for measuring the strength of this interfacial bond has been previously developed.

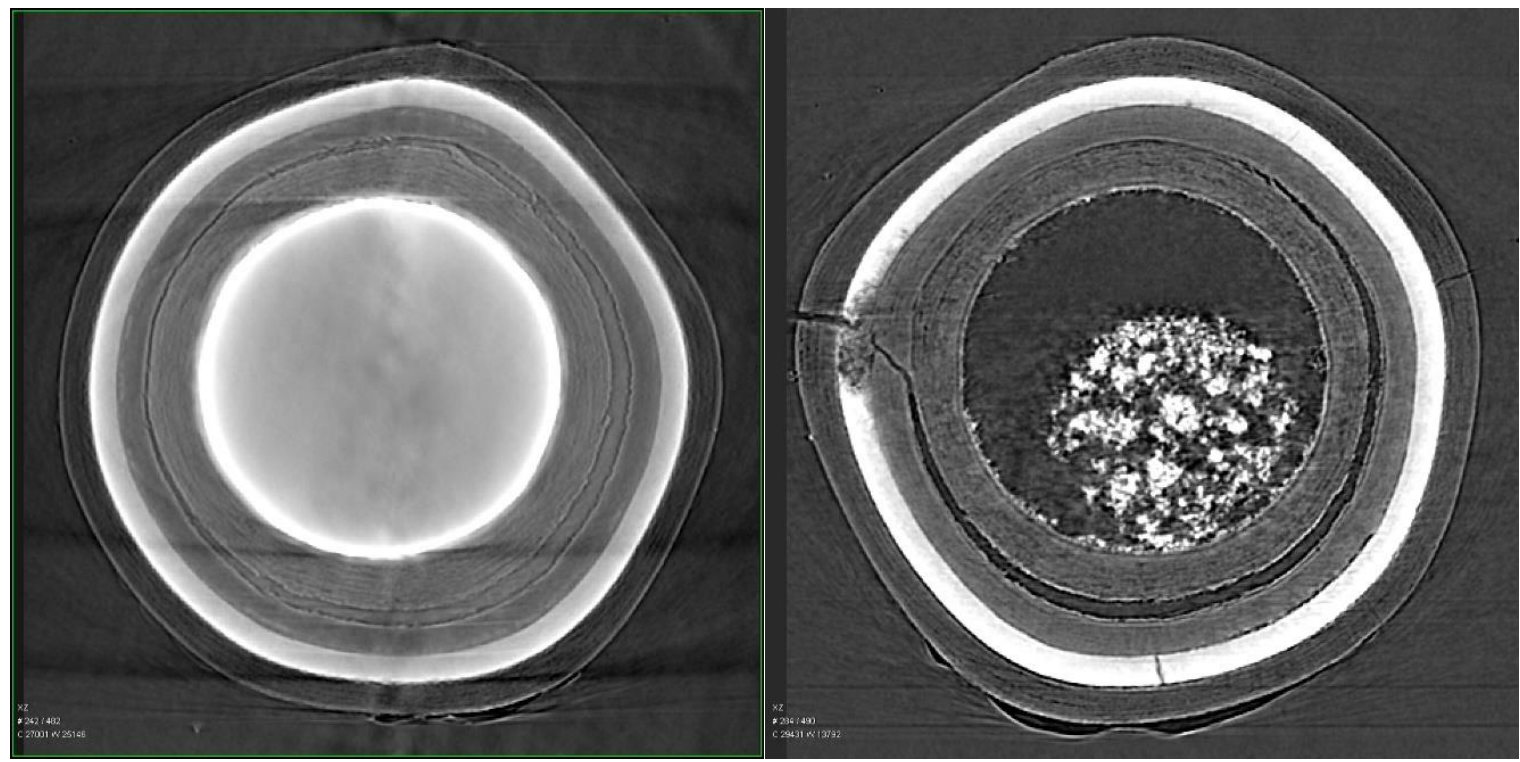

Figure 2-7. Tomographic projections of irradiated particles from the AGR program showing clean separation at the buffer/IPyC interface (left) and incomplete separation resulting in IPyC cracking leading to fission product attack on the $\mathrm{SiC}$ (right).

Both the nature and the geometry of the coating layers make the measurement of buffer/IPyC bond strength challenging. The buffer layer is composed of low density pyrolytic carbon which tends to break when handled directly, and the nested-spheres of the coating layers combined with the small size of TRISO particles preclude the use of traditional mechanical testing methods. Several approaches to creating mechanical test specimens from TRISO particles have been considered and explored, including the creation of sectioned wafers from the center of the particle for shear punch testing and attaching fixtures to the inner region of the buffer layer for tensile testing. These approaches have not yet been successful in producing a reliable means to measure buffer/IPyC bond strength, and efforts are now shifting to consider nano-indentation testing as an alternative. Initial results from comparable materials (see Figure 2-8) have shown the potential for the determination of bond strength based on crack propagation from an indentation in the IPyC layer up to and along the buffer/IPyC interface. If this method is successful, it will provide the means to determine a maximum allowable buffer/IPyC bond strength based on the past performance of TRISO fuels under irradiation, as well as providing a tool to determine coating conditions which will produce such an interface.

An additional piece of equipment has also been purchased by X-energy and installed at ORNL for the measurement of trace amounts of uranium, as is needed for Leach-Burn-Leach (LBL) analysis which is used to determine the population of some coating defects. The Kinetic Phosphorescence Analyzer (KPA) provides a rapid and inexpensive measurement of the mass of uranium in a sample. These measurements are typically completed using Inductively-Coupled Plasma (ICP) mass spectrometry, which requires sample transfer to other buildings and weeks to complete. The addition of the KPA will allow for much more rapid measurement of LBL samples, providing quick feedback for coating development. 


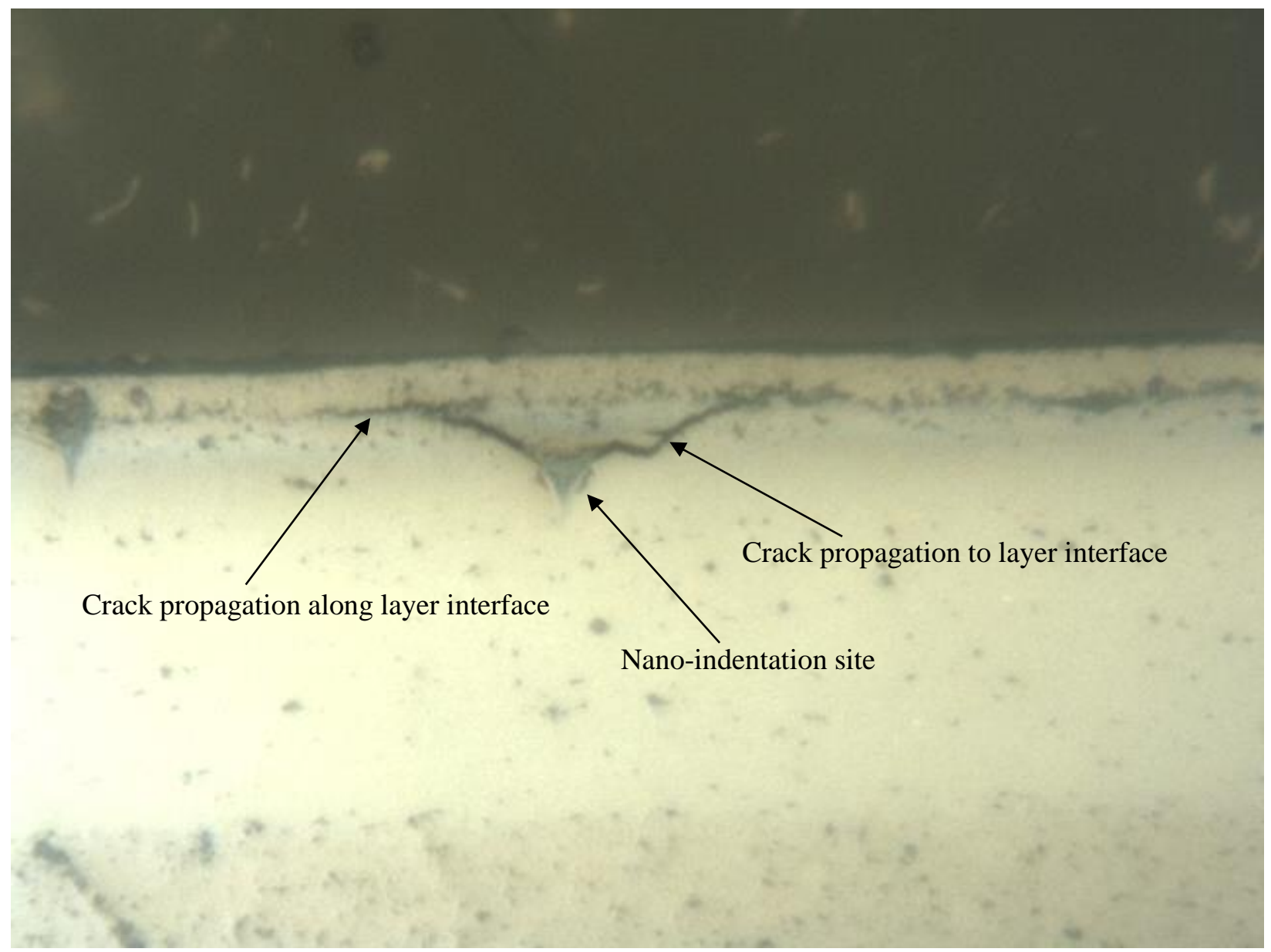

Figure 2-8. Initial testing of buffer/IPyC interface strength measurement showing crack propagation to and along the interface from nano-indentation.

\subsection{DEVELOPMENT OF PEBBLE CHARACTERIZATION METHODS}

Characterization work on pebbles in the first year has been somewhat limited as preparatory work for pressing pebbles occupied the majority of the year, and the first pebbles were not pressed until recently. During these early stages, planning and discussions were started regarding new characterization tests which will be necessary for qualification of pebble fuel. In particular, planning was done for abrasion, corrosion, and strength testing pebbles. These three areas each require significant development work, since the AGR program was focused on a prismatic-block core design utilizing cylindrical compacts for which these tests were not necessary. Now that the X-energy program is entering a phase of actual pebble production, these tests will begin development.

\subsubsection{Study on Uniformity of Pebble Density}

While only a few pebbles have been produced thus far, new characterization methods have already been developed to measure critical parameters. Test pebbles have been fabricated without any TRISO particles to test the different pebble molds and optimize pressing conditions. These matrix-only pebbles have been characterized by performing density measurements on segments from various regions of the pebble to confirm uniformity. Density measurements were performed using both the Mercury Porosimeter system, which has been used in the AGR program, and using a new geometric density measurement system based on the Archimedes principle, both of which are shown in Figure 2-9. Results from the two systems were 
compared to confirm the accuracy of the new system, which is faster and easier to operate in addition to producing less expensive waste.
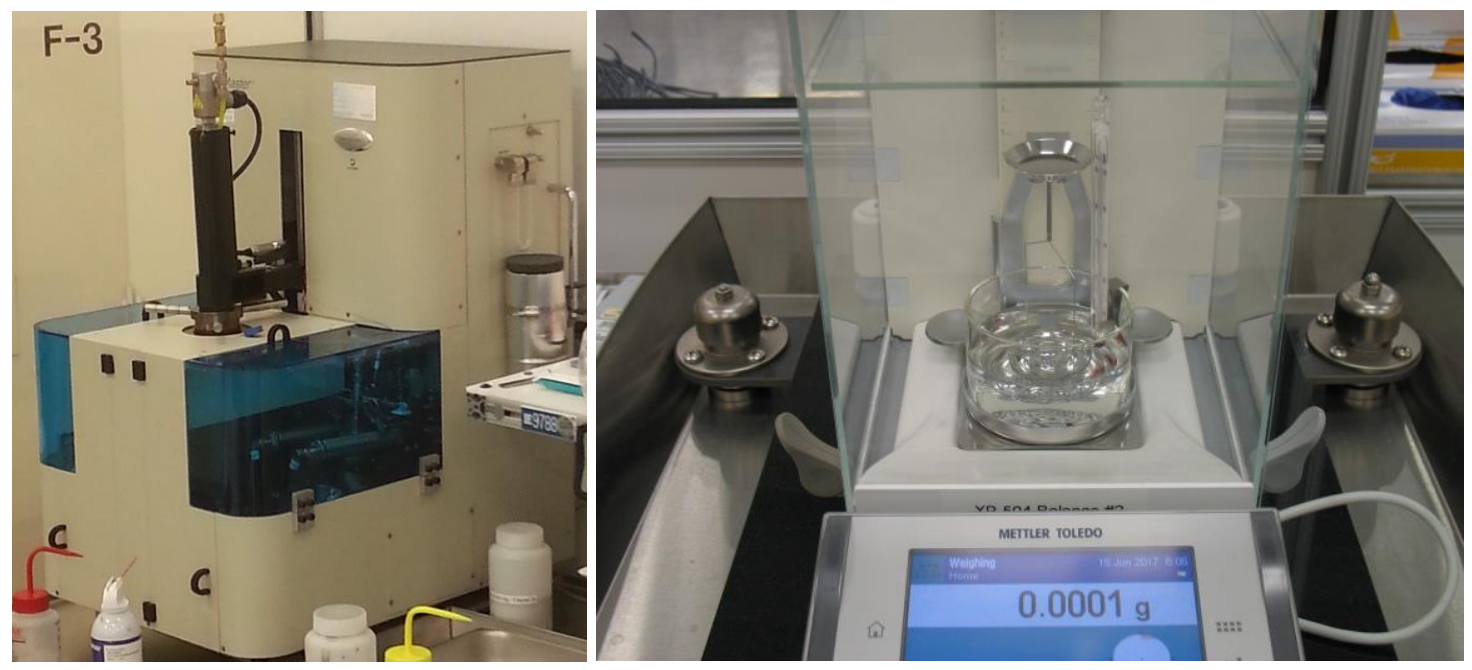

Figure 2-9. Mercury Porosimeter (left) and Archimedes system (right) used for density measurements of matrix-only pebble fragments.

\subsubsection{Measurement of Matrix Grain Boundaries and Orientation}

Additional characterization of matrix-only pebbles has been completed using the Two-Modulator Generalized Elipsometry Microscope (2-MGEM). The 2-MGEM is a specialized microscope developed at ORNL which uses elliptically polarized light to determine the reduced Mueller matrix for optically active materials, such as graphite or the TRISO coating pyrocarbons, which have a graphitic component. Two parameters in the reduced Mueller matrix, diattenuation and the Fast-Axis Angle (FAA), define the orientation of the basal plane of graphite in three-dimensional space. These parameters are important to the performance of the pyrolytic carbon layers in TRISO particles due to the non-isotropic swelling of graphite under irradiation. Typically, the 2-MGEM is used to measure the anisotropy of pyrolytic carbon layers in TRISO particles; however, it is also well-suited for characterization of the grain structure of graphite matrix in fuel pebbles. Groundbreaking new software has been developed which uses pixel-bypixel output of components of the reduced Mueller matrix from the 2-MGEM system to determine the locations of grain boundaries and the orientations of grains in graphite samples, as shown in Figure 2-10, which are difficult to measure using traditional Electron Back-Scatter Diffraction (EBSD) methods. When applied to graphite-matrix pebbles and compacts, this method provides feedback on grain size distributions and preferred orientations as functions of both pressing conditions and region, as shown in Figure 2-11. A publication detailing this novel characterization method is expected within the next year. 

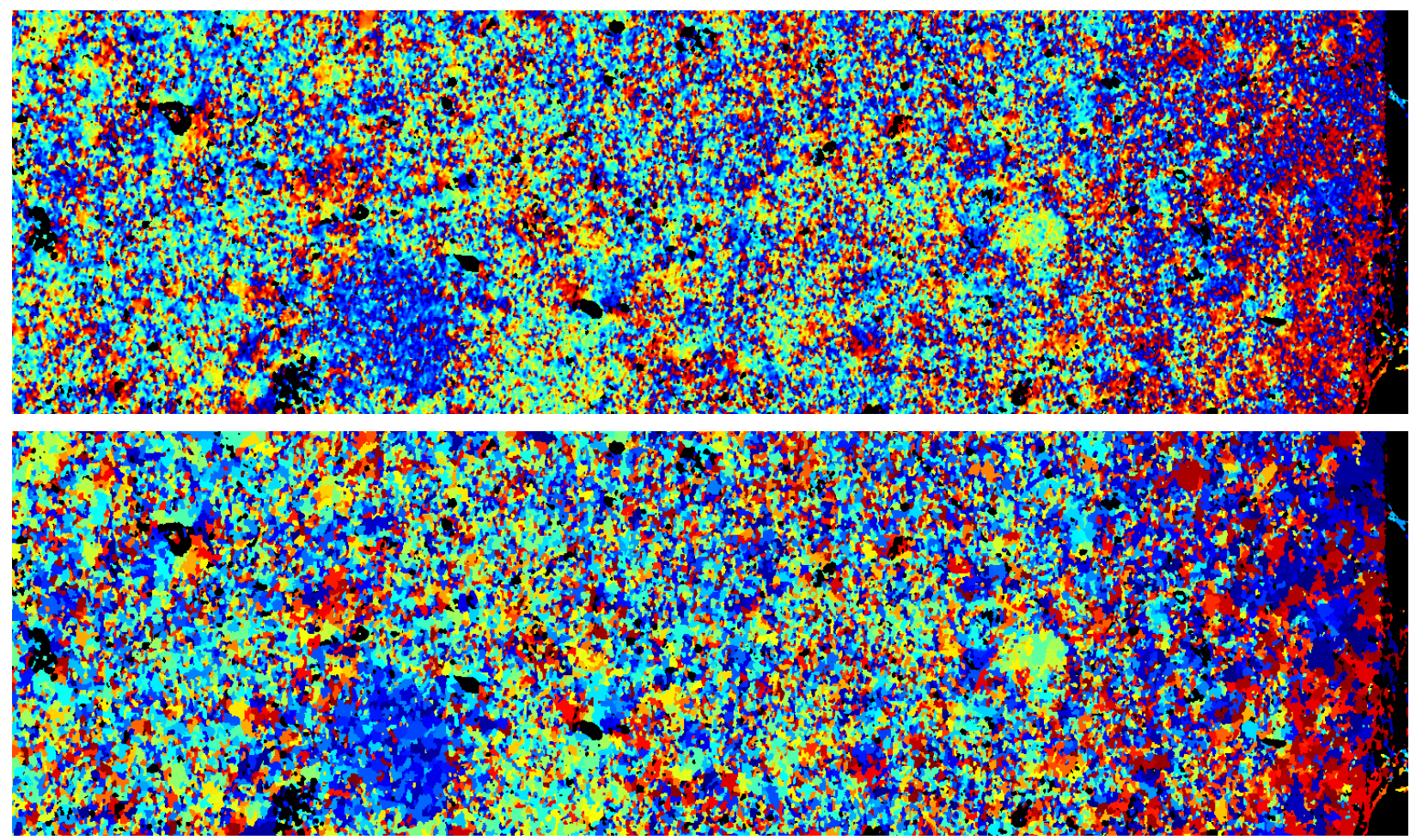

Figure 2-10. Raw FAA data measured using the 2-MGEM on a matrix-only compact (top) and processed FAA data clustered into grains (bottom). The left of the images is the center of the compact, while the right of the images is the edge. Note that the extrema of FAA (blue and red) represent angles of $0^{\circ}$ and $180^{\circ}$, and are thus very close in orientation.
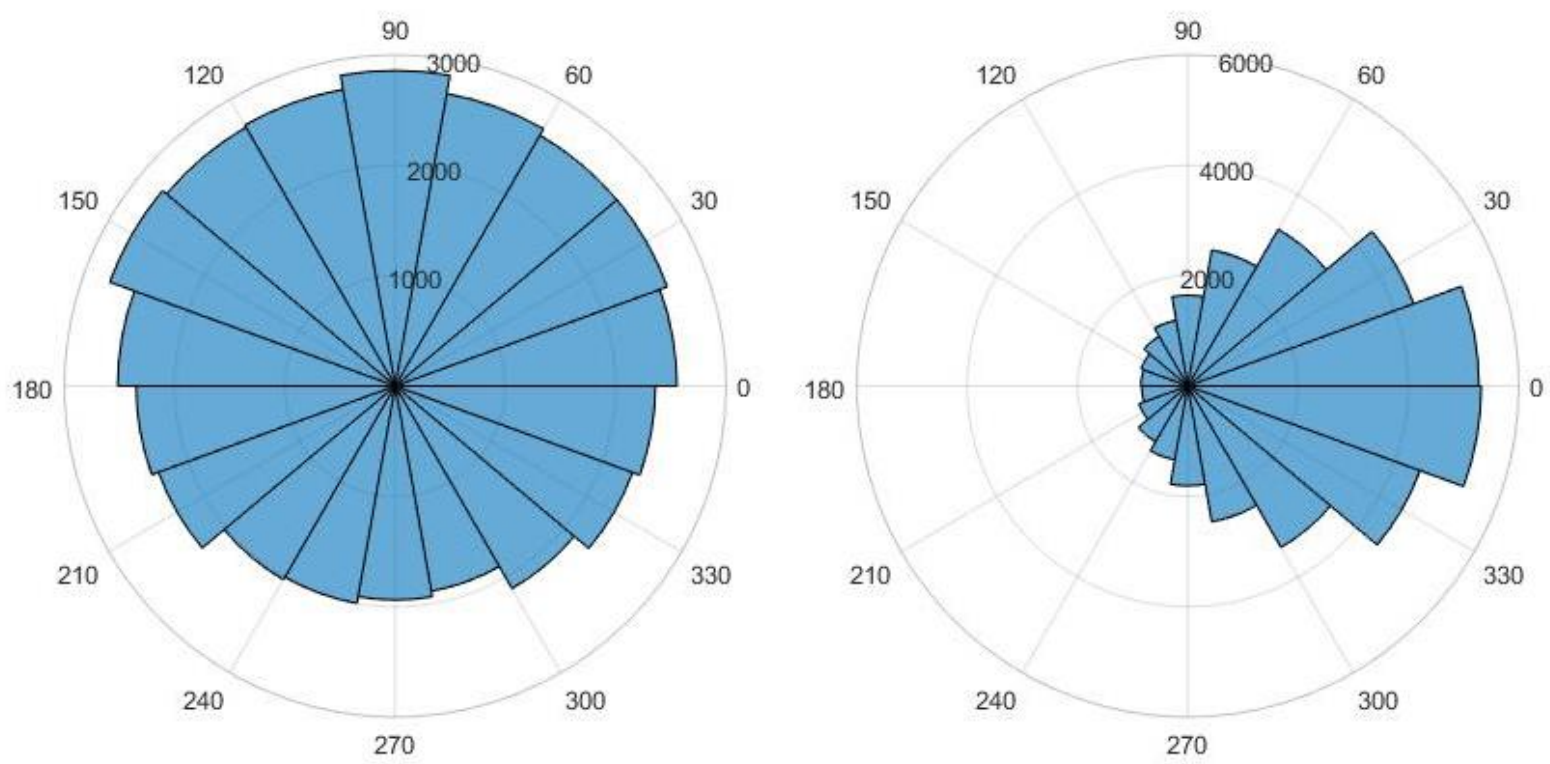

Figure 2-11. Polar histogram plots of grain orientations near the center of a matrix-only compact showing a uniform distribution of orientations (left) and near the edge showing a preference toward orientations perpendicular to the edge (right). 


\subsubsection{X-ray Tomography of Fuel Cores}

Finally, characterization of the first fuel cores containing surrogate TRISO particles has been performed using X-ray Tomography (XRT). XRT is a non-destructive technique which produces a three-dimensional tomographic representation of a sample based on mathematical reconstruction of a large number of twodimensional radiographs acquired over a range of rotational angles. Brightness in tomographs is based on $\mathrm{X}$-ray absorption, which is proportional to atomic number. XRT has been commonly used in the AGR program at ORNL for characterization of individual TRISO particles; however, a new instrument recently installed at ORNL possesses a significantly larger field-of-view and a stronger x-ray source, allowing for imaging of entire fuel cores and potentially of full pebbles. Initial tomographs have been successfully acquired for two fuel cores with surrogate overcoated particles. As shown in Figure 2-12, these tomographs clearly show the location of each of the $\sim 30,000$ particles within the fuel cores, which will be used for further analysis. Image processing software has been developed to determine parameters such as nearest-neighbor distances (see Figure 2-13), kernel volumes, and kernel sphericity. These parameters will be used to identify potentially broken particles for further analysis. While the XRT instrument used was capable of imaging the fuel cores, fuel pebbles with the addition of a fuel-free zone are at the outer limit of its field-of-view. Ultimately, x-ray imaging will be required to meet the specification on the fuelfree zone. This need, coupled with limits on accessibility to the ORNL instrument, creates a strong need for a dedicated instrument with a field of view and x-ray source optimized for TRISO pebbles.

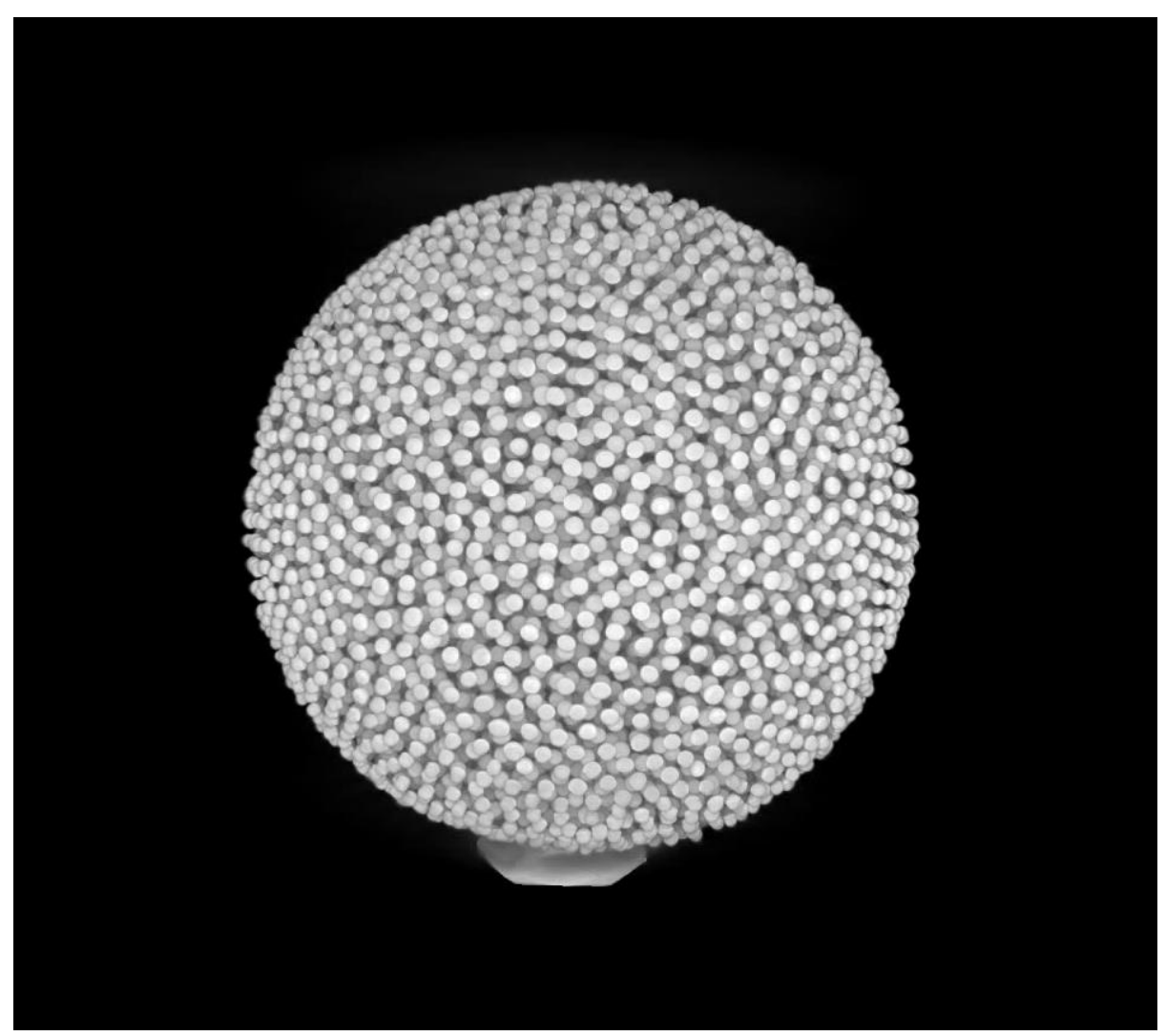

Figure 2-12. Three-dimensional representation of a surrogate kernel fuel core imaged by XRT. 


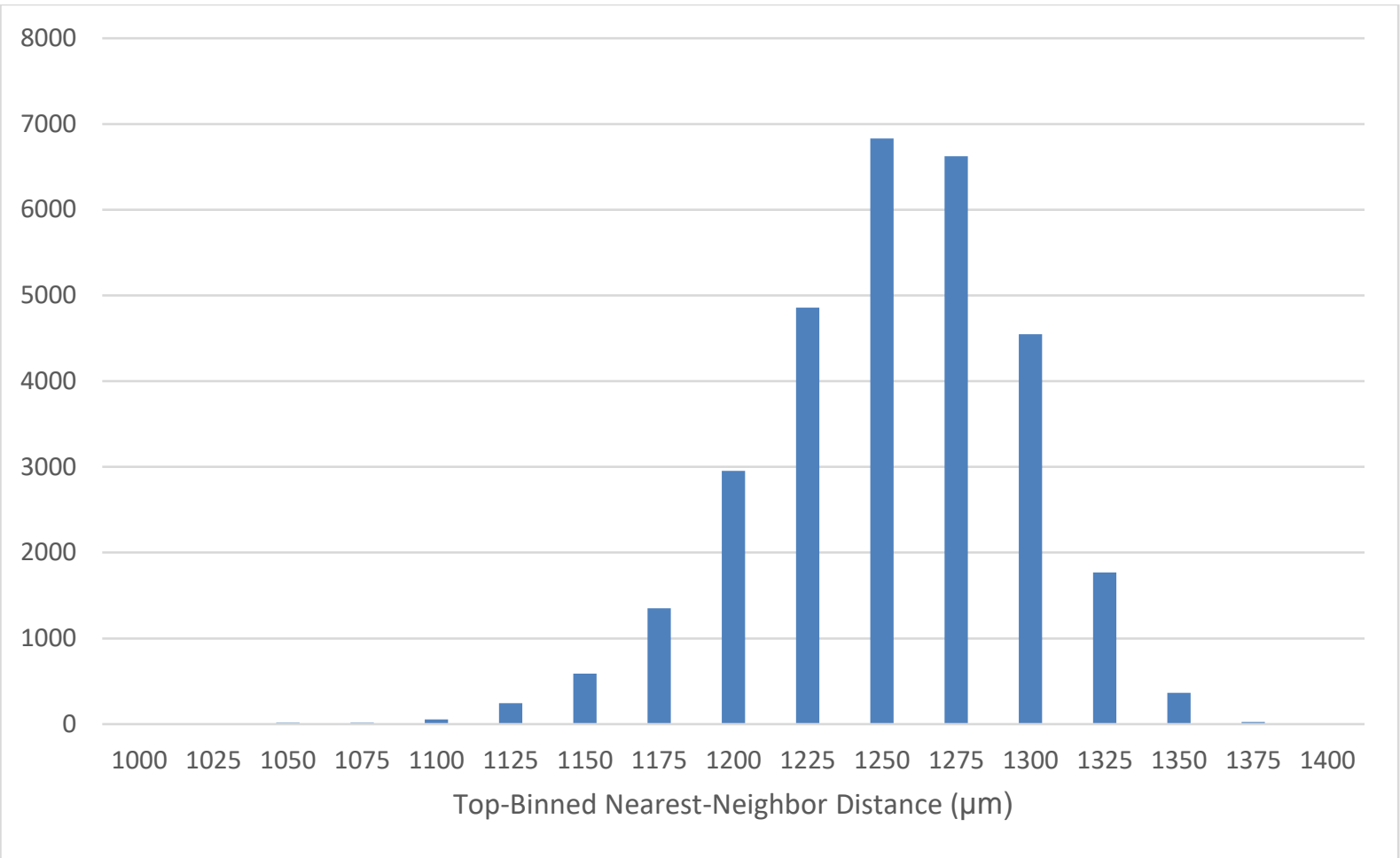

Figure 2-13. Distribution of nearest-neighbor distances for $\sim \mathbf{3 0 , 0 0 0}$ surrogate kernels in a fuel core. 


\section{KERNEL FABRICATION DEVELOPMENT}

Effort over the past year for the kernel fabrication team has included the adaptation of appropriate furnaces and other hardware necessary for kernel conversion, fine-tuning gel sphere production using various samples of carbon black and carbon dispersants, parametric studies on the various steps involved in converting gel spheres to uranium dicarbide/uranium oxide (UCO) kernels, and coupled thermodynamic and burnup calculations to determine appropriate target kernel phase fractions. These efforts have been highly successful in establishing UCO kernel fabrication capabilities at ORNL for the $\mathrm{X}$-energy project. In addition, transfer of necessary institutional knowledge to enable these processes is well underway between ORNL and on-site X-energy staff. With these primary milestones achieved, a parametric study of the carbothermic reduction and sintering processes involved is underway, with a focus on understanding the underlying thermodynamic mechanisms of the conversion process to establish a level of process understanding that will enable reliable production of thermally-stable, high-density UCO kernels.

\subsection{KERNEL CONVERSION FURNACES}

Two separate furnace systems have been identified for use in kernel conversions at ORNL. An existing Simultaneous Thermal Analyzer (STA) used for measurement of thermodynamic processes has been modified to serve as a small-scale conversion furnace with significant process analysis capabilities. In addition, an Astro high-temperature research furnace is currently in preparation for larger lab-scale kernel conversion using an approach that will inform design of a production-scale kernel conversion furnace.

\subsection{STA ADAPTATION FOR KERNEL CONVERSION}

An existing Netzsch STA at ORNL (Figure 3-1) was identified at the start of the project as an excellent system for development and optimization of kernel conversion parameters in small batches due to the thermal analysis capabilities built into the system and its ability to operate with appropriate crucible materials and in the necessary temperature and process gas conditions. The process of converting UCO kernels from gel sphere feedstock includes three steps: reduction of $\mathrm{UO}_{3}+\mathrm{C}$ to $\mathrm{UO}_{2}+\mathrm{C}$, conversion of $\mathrm{UO}_{2}+\mathrm{C}$ to $\mathrm{UO}_{2}+\mathrm{UC}$, and back-reaction of $\mathrm{UO}_{2}+\mathrm{UC}$ to $\mathrm{UO}_{2}+\mathrm{UC}_{2}$. Several modifications to the STA system were necessary to support these conversion steps. First, the gas delivery system was redesigned to accommodate an appropriate internal and external oxygen getter system as well as carbon monoxide (CO) gas mixes. $\mathrm{CO}$ monitors were also installed to allow the safe use of $\mathrm{CO}$ bearing gases. Second, specialized crucibles were designed to allow the STA to reach temperatures up to $2000^{\circ} \mathrm{C}$ while preventing carbon depletion from gel spheres and kernels into the crucibles. Finally, a calibration procedure for the microbalance, sample thermocouple, and process gas flow rates was implemented for the STA and reviewed by ORNL QA staff experts to ensure the reliability of the data generated.

At the conclusion of the first year of the project, the STA conversion setup is complete and able to reliably perform conversions on batches of up to $6 \mathrm{~g}(\sim 30,000$ gel spheres) with all necessary controls and measurement tools available for process development. 


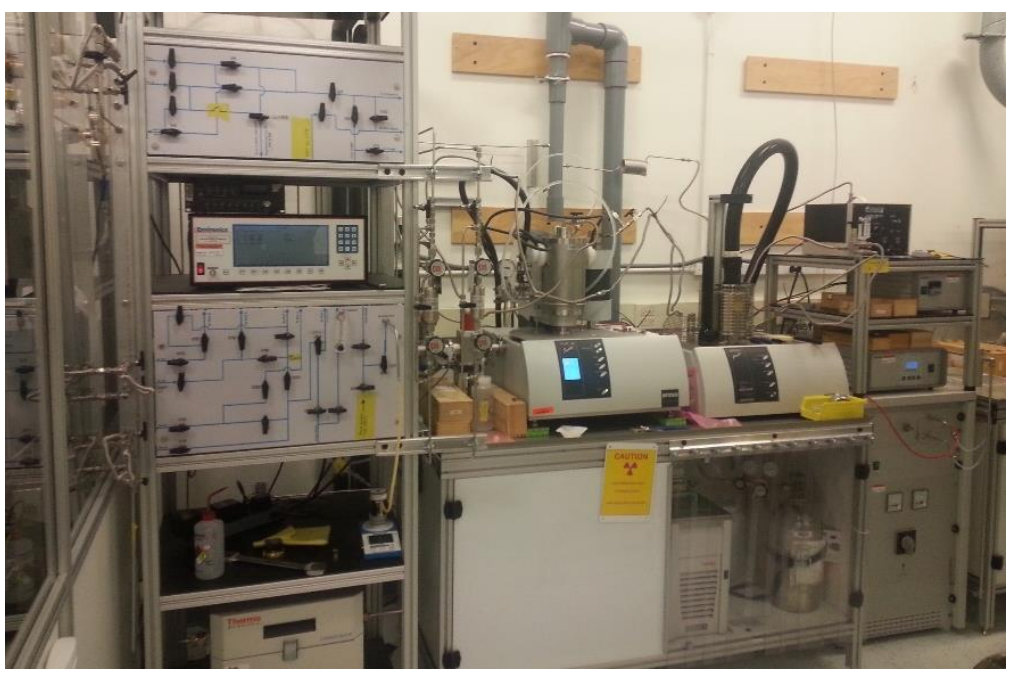

Figure 3-1. STA furnace used for small-scale kernel conversion.

\subsection{ASTRO FURNACE PREPARATION}

While the STA conversion system is well-suited to process development, its limited batch size is a significant hindrance in supporting further development work by providing large batches of kernels for TRISO coating and pebble fabrication development, as well as providing batch sizes suitable for fullyadequate characterization (larger and multiple samples must be taken from any given batch for optimal accuracy in determining some of the UCO kernel properties). To resolve this limitation, a much larger conversion system is under preparation using an Astro high-temperature research furnace (Figure 3-2). An enclosure has been built around the Astro furnace and a new gas system have been installed to allow the use of $\mathrm{CO}$ gas mixtures, as needed, and accurate control of all gases and temperatures using mass flow controllers and an integrated computer control system. The new furnace controller system has been installed and streamlines temperature control and gas control during processing. Finally, a custom crucible has been designed and is currently in fabrication which will allow for scale-up to hundreds-ofgram batches. Once the Astro furnace is ready for kernel conversions, well-characterized cross-checking runs will be completed with the STA system to verify that the scaled-up conversions perform as expected.

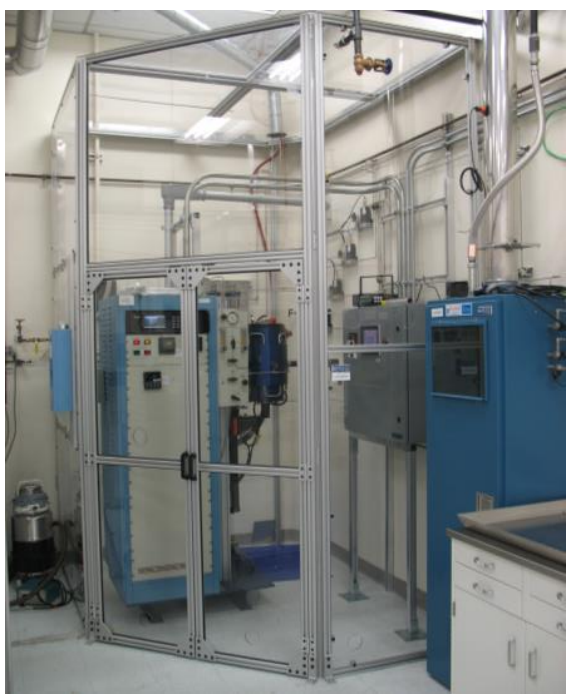

Figure 3-2. Astro Furnace in preparation for large-scale kernel conversions. 


\subsection{GEL SPHERE FEEDSTOCK MATERIALS AND METHODS}

A significant body of work has been completed on the impact of the many parameters feeding into gel sphere preparation on the final quality of the converted UCO kernels. Gel spheres are produced by dispensing an aqueous solution of uranyl nitrate, carbon, and dispersant through a vibrating nozzle into a silicone oil gelation medium (Figure 3-3). Testing of various different types of carbon black in combination with several dispersing agents in differing conditions was completed and an optimal combination was identified to produce a fine, homogenous dispersion of carbon throughout the gel sphere. X-ray Diffraction of kernels converted from gel spheres with differing carbon dispersions confirmed that this fine, homogeneous distribution was ideal for producing a consistent and full conversion to the desired $\mathrm{UO}_{2}+\mathrm{UC}_{2}$ phases in the final $\mathrm{UCO}$ kernels. A publication detailing these results is currently in the review process. This development work on gel sphere production has been used to train Tyler Reif, the X-energy detailee at ORNL working on kernel fabrication, on the full scope of the process. Tyler has demonstrated full proficiency in gel sphere fabrication, including the ability to complete runs with high yield and to independently navigate challenges associated with the process.

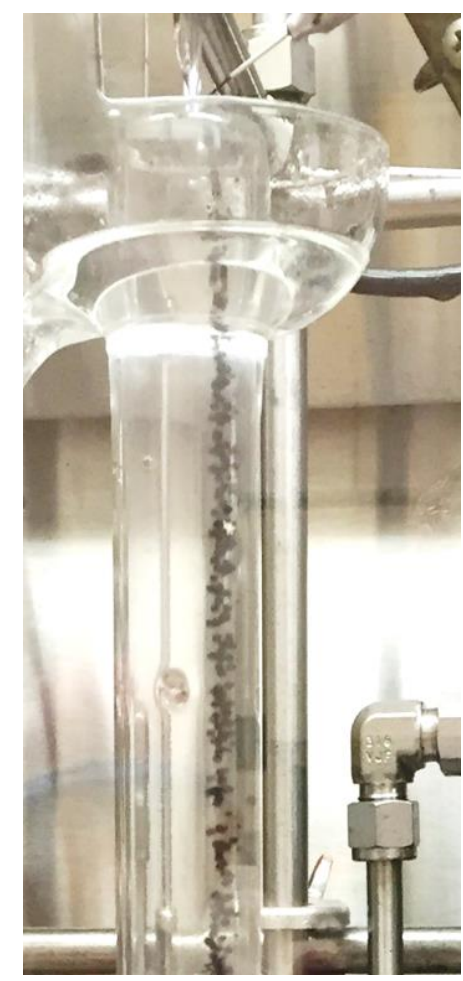

Figure 3-3. Gel spheres falling through silicon oil gelation medium after dispensing from vibrating nozzle.

A parametric study was also completed on the diameter of converted kernels as a function of the diameter of the parent gel sphere material. Upgrading by rollermicrometer was used to produce narrowlydistributed sublots of gel spheres by diameter and the mean diameters of the gel spheres before and after conversion were measured. Based on these measurements, a model was developed for gel sphere shrinkage rates, which was then used to adjust initial gel sphere diameters so that converted kernels would be in the target size range.

With the basic process for fabrication of high-quality gel spheres well-developed, ongoing efforts in UCO gel sphere process development have focused on implementation of economic recovery of uranium in leftover material for future gel sphere runs to reduce feedstock cost and waste. Initial test runs using 
recovered material are promising, and characterization of kernels from these runs is underway to confirm that a high-quality product will be maintained when using recovered feedstock.

\subsection{KERNEL CONVERSION PROCESS DEVELOPMENT}

A three-step process of converting $\mathrm{UO}_{3}+\mathrm{C}$ gel spheres to $\mathrm{UO}_{2}+\mathrm{UC}_{2}$ kernels has been developed using small-batch runs in the STA furnace. ORNL expertise in thermodynamic modeling of the U/C/O system using FactSage and an institutional CALPHAD (CALculation of PHAse Diagrams) database been successfully applied to guide the selection of dwell times, ramp rates, hold temperatures, and gas atmospheres in these tests. Under this guidance, a recipe has been developed which reliably produces UCO kernels meeting target compositions, densities, and sizes. Tyler Reif, the X-energy detailee at ORNL working on kernel fabrication, has worked closely with ORNL research staff in planning and performing these conversions to ensure necessary knowledge transfer to X-energy for kernel conversion.

Ongoing work on the kernel conversion process is focused on improving the process by reducing reaction times, scaling-up the process for larger batches of kernels, and completing basic science experiments to improve understanding of the chemistry and mechanisms of the conversion. Sensitivity studies performed on hold times, ramp rates, and gaseous atmosphere for the conversion process have shown promising initial results, as the duration of some hold times may be reduced by up to a factor of two by varying the sol-gel feedstock recipe and/or increasing temperature without adversely affecting, and sometimes improving, the quality of the converted kernels. Further studies in this area will continue to optimize the conversion process for increased industrial efficiency without sacrificing product quality.

Planned efforts to better understand the chemistry and mechanisms of the conversion process include the use of interrupted runs and evolved gas analysis. Several microstructural changes occur during the kernel conversion process, including the occasional formation of a uranium carbide skin on the outer surface of the kernel, as shown in Figure 3-4. This skin is an undesired artifact of the conversion process, but the possible timing and mechanism of its formation, as well as that of the $\mathrm{UO}_{2}$ rind, needs to be better understood. Information about the formation and microstructure of these layers will be gained by removing kernels at various points in the conversion process and analyzing the resulting phases and properties. Evolved gas analysis will be used to characterize the vapor species which are evolved at each reaction step in the conversion process. These data, coupled with a thermodynamic understanding of the U-C-O system, will be applied to obtain a better understanding of the mechanisms and parametric dependencies of the conversion process, potentially providing further guidance on its optimization.
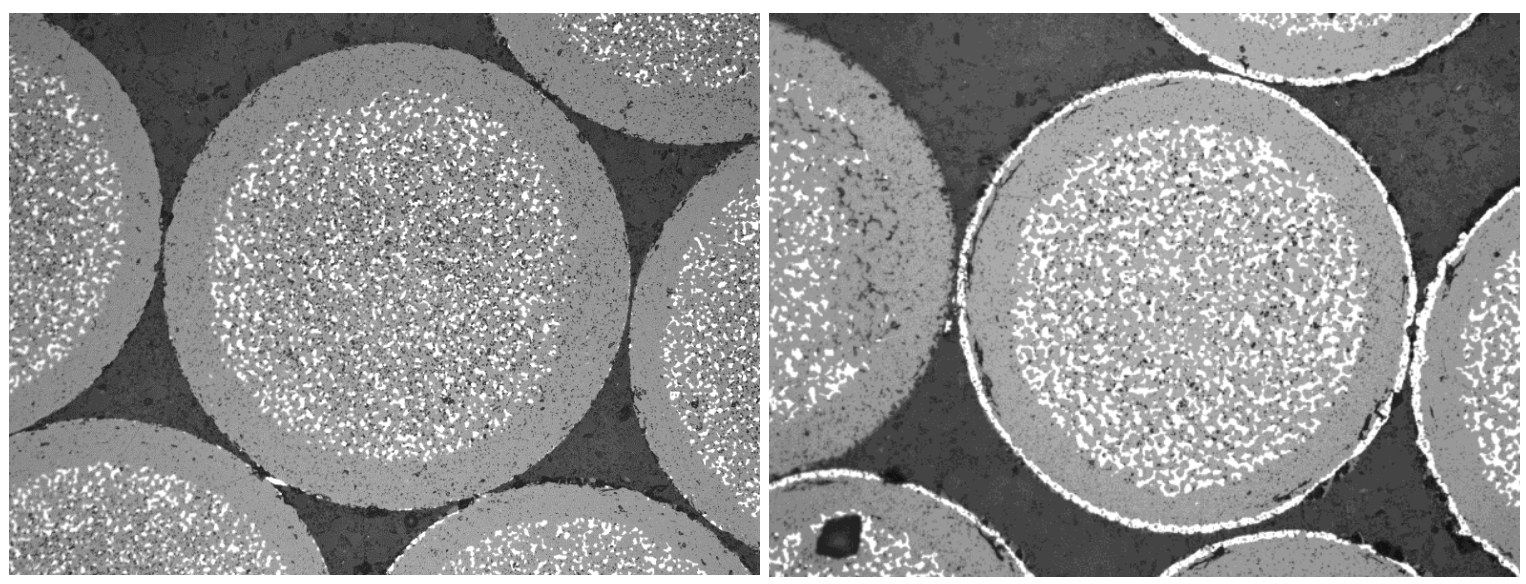

Figure 3-4. Polished cross-sections of UCO kernels without carbide skin (left) and with carbide skin (right). 


\subsection{COUPLED THERMODYNAMICS AND BURNUP CALCULATIONS}

At higher burnup, pure $\mathrm{UO}_{2}$ TRISO kernels suffer from excessive $\mathrm{CO}$ pressures and migration of $\mathrm{U}$ bearing phases into the buffer region, a phenomenon termed the "amoeba affect." In some HTGR TRISO designs, $\mathrm{CO}$ buildup from excess $\mathrm{O}$ is controlled by the inclusion of additional uranium apart from $\mathrm{UO}_{2}$ in the form of a carbide, $\mathrm{UC}_{\mathrm{x}}$ and this fuel form is designated $\mathrm{UCO}$. The added $\mathrm{UC}_{\mathrm{x}}$ provides additional material that will form oxides more readily than carbon or $\mathrm{SiC}$; however, many lanthanides are high yield fission products and exist as carbides in a UCO kernel until all of the $\mathrm{UC}_{\mathrm{x}}$ is first oxidized. Therefore, a minimum amount of $\mathrm{UC}_{\mathrm{x}}$ could be beneficial by allowing lanthanides to form oxides that are more inert and/or immobile compared to their carbides. This can only happen if burnup permits all of the initial $\mathrm{UC}_{\mathrm{x}}$ to be consumed either directly from fissioning or from reaction with liberated oxygen.

A method to determine this minimum sufficient carbide phase fraction has been developed by combining burnup calculations based on prismatic fuel simulations with thermodynamic analysis of the highly multicomponent U-C-O system including a pseudo-comprehensive inventory of elements generated as fission and activation products. These results have been used to determine minimum carbide contents for given target burnups. A paper detailing this work has been published in Annals of Nuclear Energy (McMurray et al. 2017). These results will be combined with kernel-to-kernel phase distribution data to determine mean and minimum carbide phase fractions for an eventual X-energy fuel specification. 


\section{TRISO COATING DEVELOPMENT}

Due to the well-developed state of TRISO coating capabilities at ORNL, significantly-less development work was required in the first year for TRISO coating relative to other aspects of the project. As such, the primary first year objectives for the TRISO coating team have been to produce material as needed to support pebble fabrication development efforts and to train Howard Kim, the X-energy detailee working on TRISO coating, in the fluidized-bed chemical vapor deposition process. These objectives have been successfully completed, and additional work has been performed to improve the coating process and prepare for future scale-up.

\subsection{COATING FURNACE IMPROVEMENTS}

Two TRISO coating furnaces are currently in operation at ORNL: a surrogate material coating furnace and a uranium-bearing kernel coating furnace. These furnaces were previously used in the AGR program. Several upgrades have been made to these furnaces over the past year, including new coating chambers, improved exhaust systems, and the addition of remotely-operated pneumatic gas delivery valves. These upgrades to the lab-scale coating furnaces enabled consistent delivery of coated TRISO particles to other project groups in a timely fashion. Process automation methods are being tested on the coater and work has started with commercial vendors to identify the necessary gas flow equipment and software for eventual scale-up. The scaled-up coater will feature a significantly larger coating chamber, which will increase batch sizes from $150 \mathrm{~g}$ to $\sim 1.5 \mathrm{~kg}$. Design changes to support the larger diameter coating chamber, such as a multi-inlet gas distributor, are in development.

\subsection{TRISO COATING PARAMETER DEVELOPMENT}

Important process parameters for TRISO coating layer deposition, including time, temperature, and coating gas mixtures, are dependent on specific kernel properties, especially diameter and density. Tuning of these process parameters is necessary to achieve critical target coating characteristics, including layer microstructures, thicknesses, densities, and inter-layer bonding. Initial tuning of coating parameters was completed using surrogate kernels and legacy UCO kernels from the AGR program (Figure 4-1). The properties of these kernels are relatively close to the proposed kernel parameter targets for the Xe-100; however, they are not an exact match. Thus, coating parameters were roughly-tuned using the legacy material. Fine-tuning of coating parameters will continue as sufficiently-large batches of UCO kernels are produced by the kernel fabrication team.

The process of roughly-tuning the coating parameters was useful as a training opportunity for Howard Kim, who has demonstrated proficiency in operation of the coating furnaces. In addition, an issue with buffer density dependence on reuse of cones was identified and resolved. 


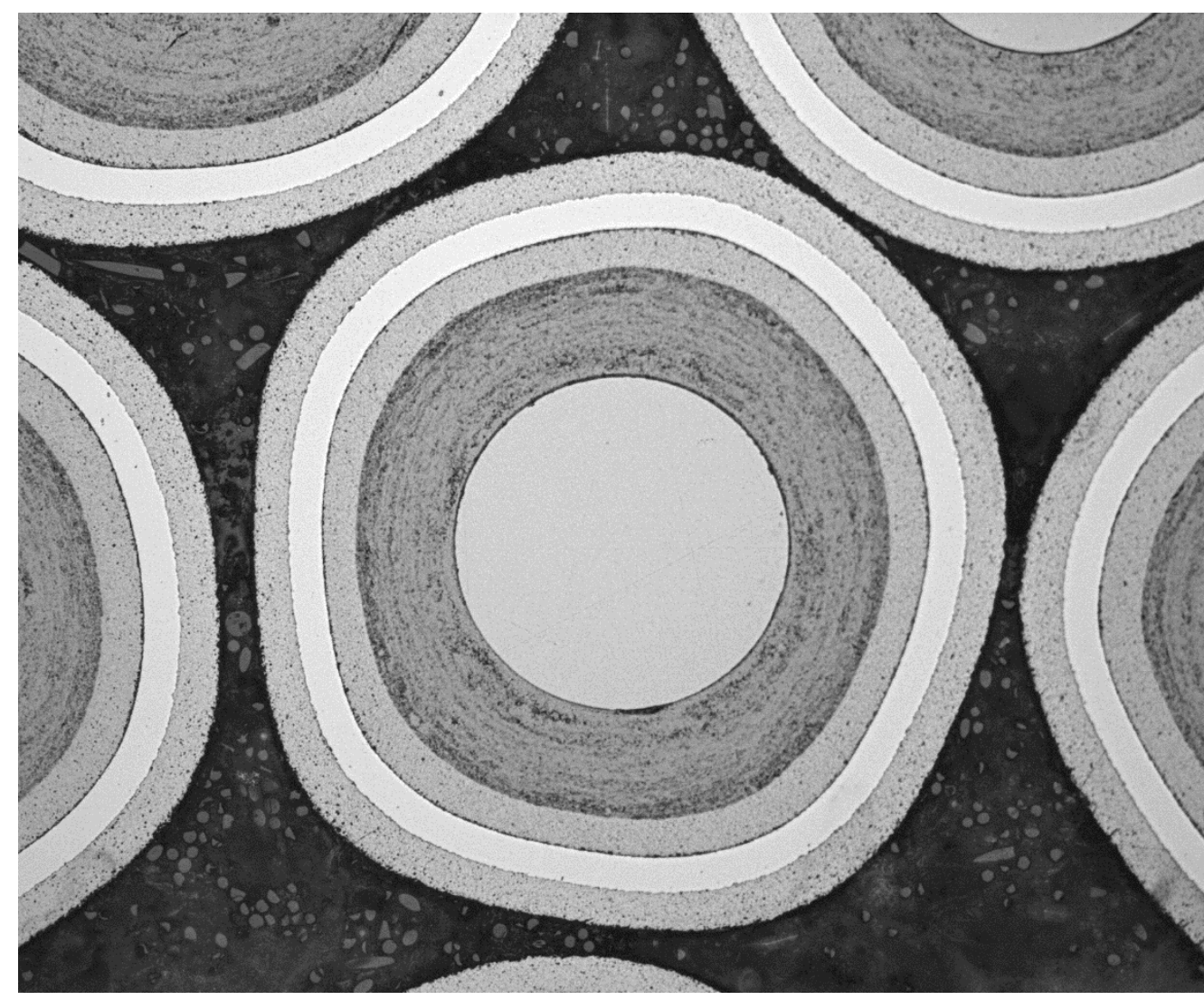

Figure 4-1. Polished cross-section of particles used for coating parameter development.

\subsection{SURROGATE TRISO PRODUCTION FOR OVERCOATING TRIALS}

One of the primary needs for the pebble fabrication team in the first year was for kilogram quantities of TRISO particles to use in overcoating and pebble pressing development. Since the kernel fabrication was still limited to small-scale runs, this need was met by fabricating large batches of surrogate TRISO particles using zirconia kernels. Since the density of zirconia kernels is significantly lower than that of UCO kernels, these surrogate particles were coated using larger kernels and a thinner buffer layer, as shown in Figure 4-2. This modification allowed the surrogate TRISO particles to be of similar size and density compared to the target UCO TRISO particles. The production of large quantities of this surrogate material allowed pebble fabrication development to proceed in parallel with kernel fabrication development, greatly accelerating programmatic progress. 


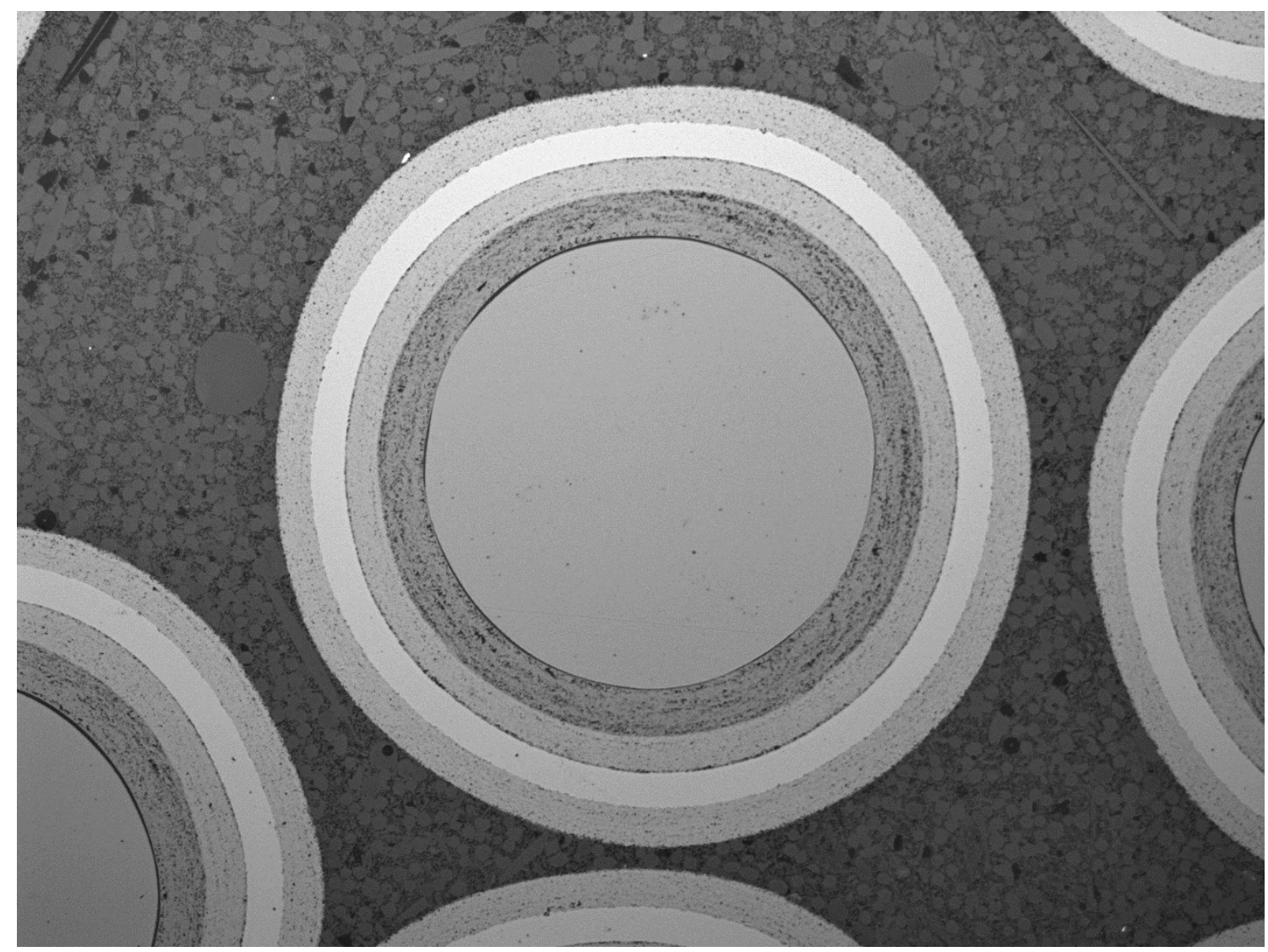

Figure 4-2. Polished cross-section of surrogate kernel particles coated with thin buffer to match target particle density.

\subsection{FLUIDIZED BED FLOW SIMULATIONS}

While the production of low-defect fraction TRISO particles is generally important for gas reactor designs, it is especially critical for development of pebble pressing methods to ensure that processinduced defects are easily identifiable. ORNL has a proven track record of producing low-defect fraction TRISO particles; however, some anomalous defects still occur due to fluctuations in particle fluidization. Computational modeling of particle fluidization during coating has been initiated to better understand this behavior. The modeling software is an open sourced CFD software being primarily developed by OpenCFD LTD, which comes bundled with governing equations and several different solvers. Relevant to particle fluidization are the multiphase and lagrangian discrete particle method solvers to resolve gas solid interactions and track particle movement within a fluidized bed.

There are several variables that can be changed to modify how the models simulate fluidization. The most significant variables include the thermal and physical properties of the gas, particles, and coater walls, as well as the gas flow and velocity. Additionally, these models can be fine-tuned by modifying the solvers source code. This software provides valuable insights into the fluidizing mechanisms within a coating chamber and provide visual representations of a fluidized particle bed, as shown in Figure 4-3. Additionally, this provides data that can be difficult to obtain experimentally, such as vorticity to analyze dead spots within the coating chamber or pressure drops for the type of fluidization. The results generated by these CFD models will be verified visually and experimentally with both the current TRISO coating furnaces and with an additional glass-wall fluidizing chamber which will be created to accurately observe the spouting behavior of a coating chamber. 

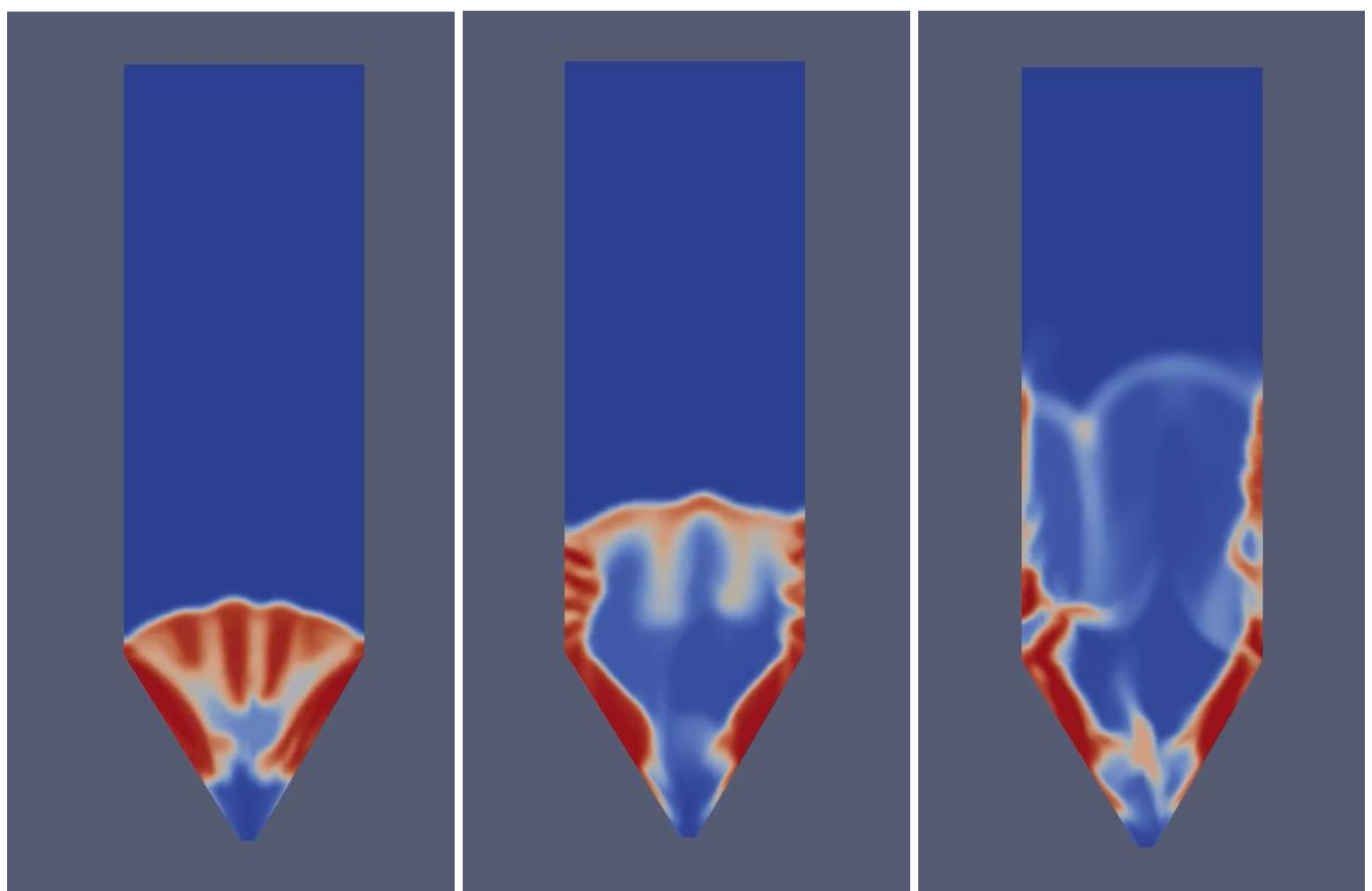

Figure 4-3. Simulation of particles in a fluidized bed at various stages of fluidization. Red areas represent large numbers of particles, white areas represent fewer particles, and blue areas represent very few particles. 


\section{PEBBLE FABRICATION DEVELOPMENT}

\subsection{PEBBLE FABRICATION EQUIPMENT ACQUISITION AND INSTALLATION}

Several critical pieces of equipment necessary for pebble fabrication have been identified, ordered, and in some cases installed at ORNL in the past year. In preparation for this new equipment, a new laboratory space in 4508-244N has been cleared of prior equipment and readied for installation of new equipment in coordination with ORNL crafts services. Laboratory 4508-244N is contiguous with the existing Coated Particle Development Laboratories and can be connected to existing labs as a single radiological area once equipment is ready for uranium materials operation. The first piece of equipment installed was a conical flo-coater system for overcoating of TRISO particles prior to pebble pressing. Isostatic and quasiisostatic methods for pressing pebbles have been investigated using existing equipment at ORNL to provide basic knowledge of both processes. The knowledge gained from these studies has been used to specify more appropriate pressing systems for both isostatic and quasi-isostatic pressing. Procurement and installation of the selected presses is planned. A CNC lathe and associated fixtures suitable for pebble machining have also been purchased and are currently awaiting installation. Finally, a furnace capable of performing the full sequence of pebble heat treatments, including carbonization, has been ordered is currently being fabricated by the vendor. The process of identifying, ordering, and installing this pebble fabrication equipment has been completed early in the project to ensure that critical capabilities are in place before they are needed and to eliminate unnecessary delays.

\subsection{PEBBLE FEEDSTOCK MATERIALS TESTING AND SELECTION}

A broad empirical study on the quality of matrix-only compacts pressed from pebble matrix materials has been completed to provide a down-selected set of feedstock materials for consideration in actual pebble fabrication. Pebble matrix is composed of a mixture of natural graphite, synthetic graphite, and resin. At least ten varieties of each of these materials were obtained from several vendors for this initial scoping study. Individual materials and pressed pellets from various permutations were considered using a comprehensive test matrix including impurity analysis via glow discharge mass spectrometry, compressive strength, tap density, compressed density, dimensional changes during heat treatment, morphology via scanning electron microscopy, char yield, and TGA/DTA measurements. The exceptionally-broad range of analysis methods employed in this study were enabled by the utilization of existing characterization equipment available in various laboratory groups at ORNL, as well as the input of several ORNL experts in fabrication and testing of graphite-based materials.

The parameter given the greatest weight in this analysis was compressive strength, as the primary function of the pebble matrix is to protect the embedded TRISO particles. At the conclusion of this analysis a down-selected list of several natural graphites, synthetic graphites, and resins was generated for further use in pebble fabrication.

\subsection{OVERCOATING PROCESS DEVELOPMENT}

The selection, purchase, installation, and initial testing of an overcoater was a critical milestone for pebble fabrication accomplished in the first year. Overcoating is the process of layering graphite matrix material onto the surface of TRISO particles before compaction into a final fuel form. Once a potentially suitable overcoater was identified, a demonstration was completed using surrogate TRISO particles which showed the potential of the instrument, with some development work, to meet programmatic requirements for overcoating. After installation of the overcoater at ORNL (Figure 5-1), process development has focused on optimization of coating parameters including powder and spray feed rates to minimize matrix powder loss, maximize matrix adhesion to particles, and minimize overcoating thickness variation. An effective initial set of parameters for overcoating of surrogate TRISO particles has been developed, which has 
provided necessary material for the fabrication of the first TRISO-bearing fuel cores. Further optimization of the overcoating process is ongoing, and some minor adjustments may be necessary when transitioning from TRISO particles containing surrogate to those bearing UCO kernels.

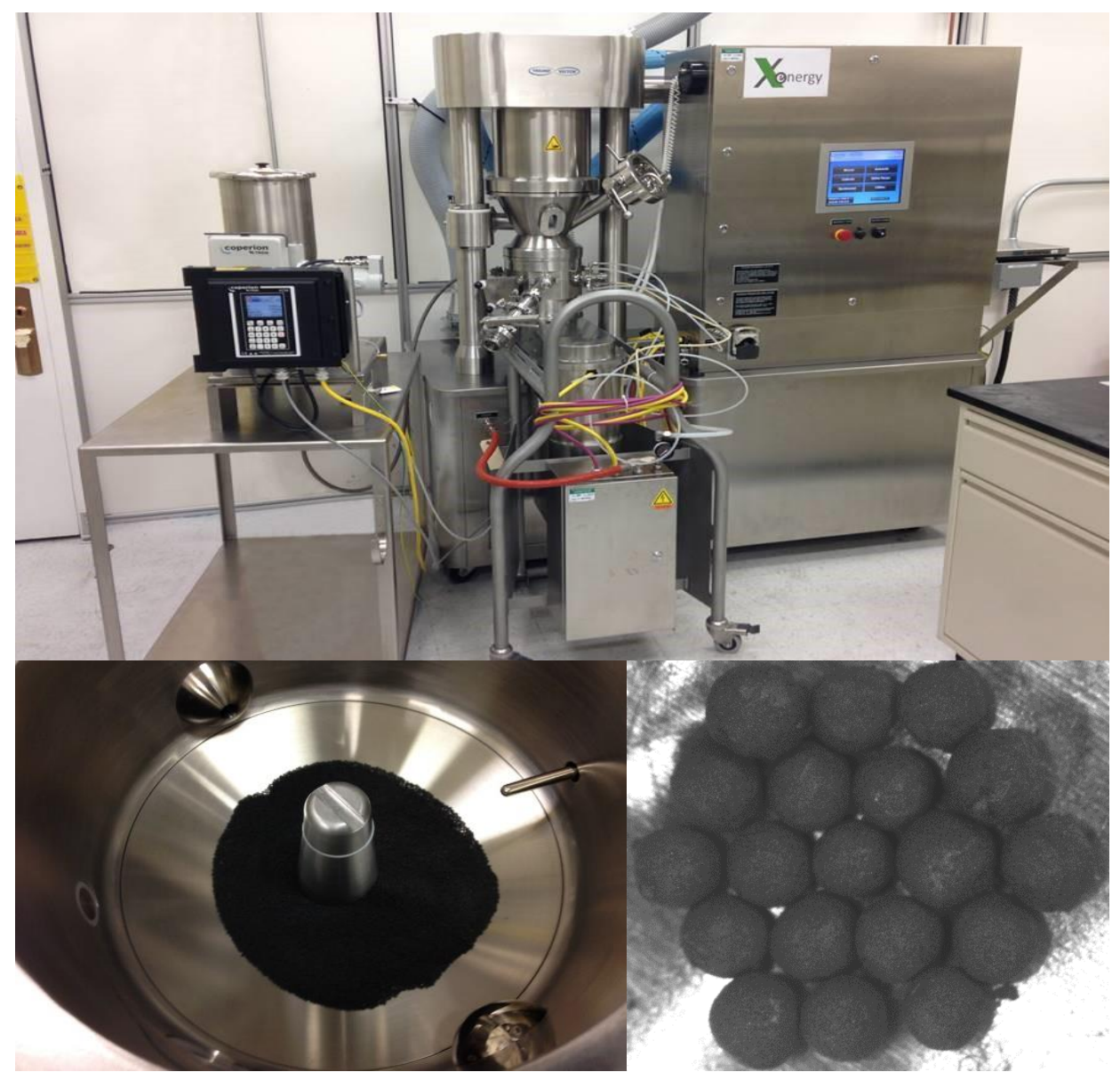

Figure 5-1. Overcoater installed at ORNL (top), TRISO particles loaded in the overcoater chamber (left), and overcoated particles (right).

\subsection{PEBBLE PRESSING PROCESS DEVELOPMENT}

Development work for pebble pressing has proceeded along two parallel paths: isostatic pressing and quasi-isostatic pressing. Isostatic pressing is a more direct method for ensuring isotropic properties in resulting pebbles; however, it is useful to compare to a German-like quasi-isostatic pressing to better understand each methods strength and weaknesses and determine which might be the most economical for high-throughput manufacturing. Custom molds for both pressing methods (Figure 5-2) have been rapidly fabricated by first 3D-printing negatives of the mold components, then casting the necessary mold pieces. After overcoming initial challenges related to air entrapment within molds, this method has allowed for rapid turnaround on testing of mold designs and mold materials. Proper mold design is a crucial part of the pebble fuel development process. 


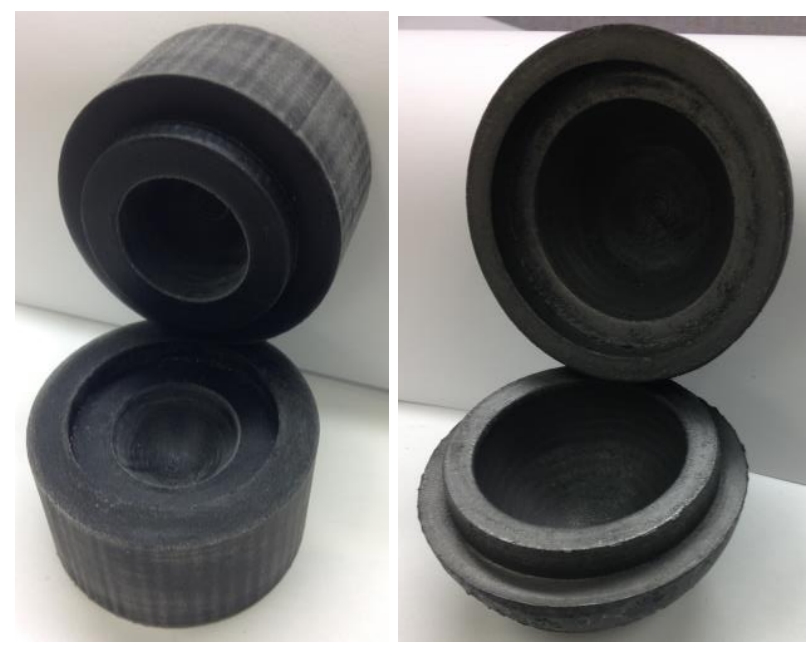

Figure 5-2. Molds for quasi-isostatic pressing (left) and isostatic pressing (right).

Initial matrix-only test pebbles have been pressed using both isostatic and quasi-isostatic methods (Figure 5-3). Characterization of matrix density and grain structure has been started on these pebbles to determine the uniformity of density and microstructure throughout, and testing on pebble strength and dimensional changes as a function of carbonization heating rate is planned. Fabrication of the first fuel cores containing surrogate overcoated particles has been completed (Figure 5-3), and preliminary analysis by XRT indicates that particles are evenly distributed as desired and there are no signs of crushed particles as a result of the pressing process.
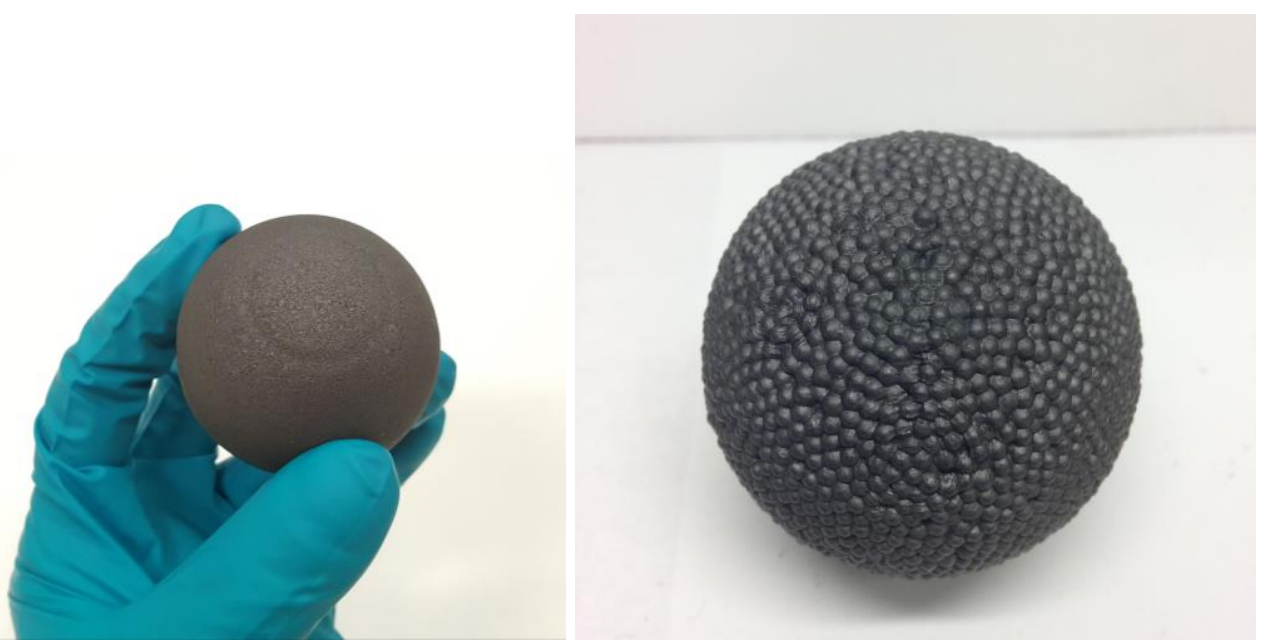

Figure 5-3. Pressed matrix-only pebble (left) and fuel core (right). 


\section{REFERENCES}

Hunn, J.D., C.A. Baldwin, T.J. Gerczak, F.C. Montgomery, R.N. Morris, C.M. Silva, P.A. Demkowicz, J.M. Harp, S.A. Ploger, I.J. van Rooyen, K.E. Wright. 2014. "Detection and Analysis of Particles with Failed SiC in AGR-1 Fuel Compacts." Paper HTR2014-31254, Proceedings of the 7th International Topical Meeting on High Temperature Reactor Technology (HTR2014), Weihai, China, October 27-31, 2014. Also published in Nucl. Eng. and Design 306: 36-46.

McMurray, J.W., T.B. Lindemer, N.R. Brown, T.J. Reif, R.N. Morris, J.D. Hunn. "Determining the Minimum Required Uranium Carbide Content for HTGR UCO Fuel Kernels." Annals of Nuclear Energy 104 (2017) 237-242. 